\title{
Martín García Mérou y su vida diplomática en Estados Unidos, 1896-1900 y 1901-1905
}

Paula Bruno*

Recibido el 20 de noviembre de 2018; aceptado el 3 de diciembre de 2018

\section{RESUMEN}

Martín García Mérou (1862-1905) tuvo una destacada participación en la vida intelectual y diplomática de su época a escala transnacional. Se desempeñó en distintos cargos del servicio exterior argentino y fue poeta, periodista, crítico, ensayista, historiador, cronista, biógrafo y novelista. Nacido en Argentina, García Mérou estuvo la mayor parte de su vida instalado en otras geografías. Residió en naciones latinoamericanas, como Venezuela, Colombia, Perú, Paraguay y Brasil, en Estados Unidos, además de España y Alemania. Combinó esas residencias con sus labores intelectuales, y sus obras sobre la vida cultural y la historia de estos escenarios, lejos de ser los clásicos relatos de viaje o impresiones de la época, son estudios sólidamente informados sobre configuraciones sociales y dinámicas culturales que dan cuenta de los procesos modernizadores del cambio de siglo XIX al XX. Este ensayo centra la atención en una parte de la trayectoria cultural y diplomática, la de sus estancias en Estados Unidos. Se presta atención a sus observaciones sobre la guerra de 1898, las Conferencias Panamericanas, el panamericanismo y el clima de ideas que suele caracterizarse como el del "primer antiimperialismo latinoamericano". A su vez, se realiza un análisis crítico de sus escritos para conocer las representaciones sobre tópicos de su época, a saber: la consolidación de las estructuras estatales en América Lati-

* CONICET/Universidad Torcuato Di Tella, correo electrónico: pbruno@utdt.edu 
na, las visiones sobre los Estados Unidos y su proyección internacional, sus consideraciones sobre el servicio exterior argentino, entre otros aspectos. Para ello, se revisan fuentes provenientes del Archivo Histórico de Cancillería Argentina, del Fondo García Mérou del Instituto Bibliográfico Zinny, artículos de prensa y publicaciones periódicas y obras editadas.

Palabras clave: diplomacia, vida intelectual, Estados Unidos, panamericanismo, antiimperialismo.

\section{Martín García Mérou and his diplomatic life in the United States, 1896-1900 and 1901-1905}

\section{AbSTRACT}

Martín García Mérou (1862-1905) participated profoundly in the intellectual and diplomatic life of his time and on a transnational scale. He served in various positions in the Argentine foreign service and was a poet, journalist, critic, essayist, historian, chronicler, biographer and novelist. Born in Argentina, García Mérou spent most of his life abroad. He lived in Latin American countries, such as Venezuela, Colombia, Peru, Paraguay and Brazil, in the United States, and in Spain and Germany. He combined those residences with his intellectual activities and his works on the cultural life and the history of those scenarios, far from being the classic travel stories or impressions of the time, are solidly informed studies on social configurations and cultural dynamics that account for the modernizing processes of the 19th to 20th centuries. This essay focuses on a share of the cultural and diplomatic trajectory from his stays in the United States. Attention is given to his observations on the 1898 war, the Pan-American Conferences, Pan-Americanism and the climate of ideas often characterized as the "first Latin American antiimperialism". At the same time, a critical analysis of his writings is made to understand the representations about topics of his time, specifically: the consolidation of state structures in Latin America, the visions about the United States and its international projection, and his thoughts on the Argentine foreign service, among other aspects. To this end, sources from the Historical Archive of the Argentine Chancellery, the García Mérou Fund of the Zinny Bibliographic Institute, newspaper articles and periodicals and edited works are reviewed.

Key words: diplomacy, intellectual life, United States, Pan-Americanism, antiimperialism. 


\section{INTRODUCCIÓN}

T os estudios sobre el ámbito diplomático en la Argentina de cambio del ـiglo XIX al XX no cuentan con una consolidada tradición historiográfica. Son contados los libros que se detienen especialmente a dar cuenta de la organización del servicio exterior y de las reformas que se dieron a lo largo del tiempo; ${ }^{1}$ se destacan algunas historias de la política exterior argentina de largo plazo, que son utilizadas como referencias; ${ }^{2}$ y se han producido, además, algunos libros breves con semblanzas de diplomáticos. ${ }^{3}$ Destacados libros de historia del período de cambio del siglo XIX al XX, publicados en las últimas décadas, por su parte, no incluyen un capítulo destinado a dar cuenta de las relaciones de Argentina con el mundo en sentidos más amplios que los de carácter comercial.

La vida diplomática como ámbito de despliegue cultural e intelectual no cuenta aún con una historia desde el punto de vista de los actores y las dinámicas que allí se desenvolvieron. ${ }^{4}$ Este ensayo ofrece algunos indicios respecto de lo que en la época se denominaba "vida diplomática" en un escenario específico: la legación de Estados Unidos y México, con sede en Washington y a la luz de la experiencia de Martín García Mérou, que allí estuvo designado entre 1896-1900 y 1901-1905.

En una carta dirigida a Charles R. Rohl, cónsul general de la República de Venezuela, que García Mérou escribió en 1899, se refiere a sus "continuas peregrinaciones diplomáticas” y trata de resumir una parte de las mismas con estas palabras: “desde 1887 regresé a la carrera diplomática después de una interrupción de un año y serví a mi patria sucesivamente en el Paraguay, en el Perú, en el Brasil y desde 1896 en Washington”. ${ }^{5}$ Estos destinos no fueron los únicos, se suman a ellos: Colombia, Venezuela, España y Alemania. ${ }^{6}$ Su vocación diplomática comenzó a los 19 años, y en un momento de incertidumbre vital obtuvo un nombramiento como oficial secreta-

Véase Solveira, B., La evolución del servicio exterior argentino entre 1852 y 1930.

Véase Cisneros, A. y Escudé, C (dirs.), Historia general de las relaciones exteriores de la República Argentina.

3 Me refiero a la Colección Los Diplomáticos, publicada por CARI y disponible en línea: $<$ http://www.cari.org.ar/recursos/diplomaticos.html>.

4 Para una historia general sobre la diplomacia en estos años puede verse Mősslang, M. y Riotte, T. (eds.), The Diplomats’ World: A Cultural History of Diplomacy, 1815-1914.

5 Carta de Martín García Mérou a Charles R. Rohl, Washington, 24/08/1899. Archivo Histórico de Cancillería Argentina, Serie Misiones al Exterior, Caja AH 118.

6 Para una mirada de largo plazo sobre la trayectoria de Martín García Mérou puede consultarse: Bruno, P., Martín García Mérou. Vida intelectual y diplomática en las Américas. 
rio ad honorem de una misión encargada a Miguel Cané en Venezuela y Colombia. Las observaciones de este periplo que encararon juntos cuenta con un doble registro: están recogidas en las páginas de En viaje de Cané, ${ }^{7}$ y en Impresiones de García Mérou (ambos libros fueron publicados en 1884). Esta asociación iniciática entre estadías diplomáticas y la escritura de un libro para recoger inquietudes y observaciones inauguró lo que sería una tendencia en su vida: la de escribir estudios y obras de investigación sobre los países en los que se instaló con cargo y designaciones diplomáticas. Sus libros nacidos de las experiencias diplomáticas, lejos de ser los clásicos relatos de viaje de la época, son estudios ordenados y sólidamente informados sobre configuraciones culturales y políticas basadas en información consistente y que presentan reflexiones sobre diferentes procesos del cambio de siglo XIX al XX.

Sus experiencias diplomáticas se desplegaron en momentos especialmente densos para la historia del continente americano. Primero como secretario de Cané, y luego al permanecer con cargo interino de encargado de negocios en Colombia, observó Venezuela en el momento en que se consolidaba el mandato de Antonio Guzmán Blanco y se discutían las ventajas de la Constitución de 1881; estuvo en Colombia en los años de mandato de Rafael Núñez cuando se daban las condiciones para la firma del Tratado Arosemena-Guzmán (1881-1882) por la cuestión de límites entre Colombia y Venezuela; como ministro residente en Paraguay estuvo allí el año en el momento en que se firmó el Tratado Aceval-Tamayo (1887) para resolver parte del conflicto limítrofe con Bolivia; durante sus años en Lima vio el levantamiento civil luego del alzamiento contra Andrés A. Cáceres y fue testigo de las tensas y frustradas negociaciones para resolver el conflicto entre Chile y Perú por Tacna-Arica (iniciadas en 1894); llegó a Brasil en pleno clima de movimientos sociales, evaluó los efectos de la revuelta de Canudos y la hegemonía de Floriano Peixoto, además allí estaba en el contexto de la firma del mencionado Laudo Cleveland (1895) que resolvió el conflicto limítrofe entre Argentina y Brasil por el territorio Misiones-Palmas; como se estudia en este ensayo, se instaló en Estados Unidos en 1896 y permaneció frente a la legación hasta 1905 con una breve interrupción. Fue, por lo tanto, un particular testigo de los efectos de la guerra de independencia de Cuba en 1895, de la guerra entre España y la nación del Norte por el control de las últimas colonias españolas en 1898, del ascenso norteamericano en tanto potencia expansionista; participó activamente, además, en la II Conferencia

\footnotetext{
7 Cané, M., En viaje.
} 
Panamericana realizada en México en 1901-1902, donde se dieron los debates de arbitraje que desembocaron en la Doctrina Drago.

En suma, su trayectoria en la diplomacia - tarea a la que abocó más de la mitad de su vida - estuvo eslabonada por hitos nacionales, bilaterales y continentales de amplia repercusión. Este artículo se detiene en algunos aspectos de su itinerario y estudia cómo García Mérou presentó diagnósticos respecto de la vida diplomática y entendió su propio rol; cómo definió una serie de funciones ligadas a la generación de conocimientos e información con el objetivo de oficiar de puente entre dos naciones - en este caso Argentina y Estados Unidos-; cómo comprendió los fenómenos ligados al panaamericanismo y el despliegue norteamericano en el continente. En este último sentido, se hace también foco en la guerra entre España y Estados Unidos de 1898, en las dos primeras Conferencias Panamericanas.

\section{SER DIPLOMÁTICO ARGENTINO EN ESTADOS UNIDOS EN EL FIN DE SIGLO}

Entre la diplomacia entendida como un saber de Estado por antonomasia y practicada por expertos, y la diplomacia asociada al ocio, los tiempos muertos y el aburrimiento, ${ }^{8}$ se desplegaron distintas trayectorias que permiten dar cuenta cómo algunos intelectuales fueron diplomáticos en un momento cargado de tensiones y de ambivalencias en las Américas.

Los años anteriores a las misiones de García Mérou, el cargo de Ministro Plenipotenciario y enviado especial a Estados Unidos ${ }^{9}$ lo habían ocupado Vicente Quesada (1885-1892) y Estanislao Zeballos (1893-1894); ambas experiencias ofrecen algunos indicios respecto de lo que significaba ejercer esas funciones y de los márgenes de autonomía que los representantes argentinos tenían en la legación.

Vicente Quesada, en sus anotaciones de Recuerdos de mi vida diplomáti$c a$, no titubeaba al señalar que podía ser nombrado para ejercer funciones en Estados Unidos sin dominar de manera fluida el idioma inglés y que solamente estando allí retomaba lecciones cinco días a la semana para recuperar un idioma que había aprendido fragmentariamente en la juventud. ${ }^{10}$ Por su parte, da cuenta de cómo decidió no participar de la I Conferencia Panameri-

8 Para la idea de la diplomacia como espacio de aburrimiento y ocio, véase Viñas, D., De Sarmiento a Dios. Viajeros argentinos a USA; y Viñas, D., Literatura argentina y realidad política. De los jacobinos porteños a la bohemia anarquista.

9 Solo desde 1914, con una reforma propiciada por Rómulo Naón, el cargo se formaliza con el nombre de Embajador.

10 Quesada, V., Recuerdos de mi vida diplomática. Misión en Estados Unidos (1885-1892), p. 7. 
cana que se realizaba en Washington durante su estadía allí como representante argentino, y prefirió pedir licencia y viajar a París para visitar la Exposición Universal. ${ }^{11}$ Por último, cabe destacar que durante los años de su legación escribió un texto de carácter crítico sobre las costumbres norteamericanas que se publicó con seudónimo, Domingo de Pantoja, en 1893. En suma, el Vicente Quesada que se instaló en Estados Unidos y vivió allí siete años, lejos estaba, a juzgar por su producción, de ser el intelectual del derecho internacional de la década de $1880 .{ }^{12}$

Estanislao Zeballos, quien había sido Ministro de Relaciones Exteriores y Culto entre 1889 y 1892, en cambio, instalado en Washington por un breve período se mostró como un diplomático activo, atento a las formas en las cuales convenía pensar las relaciones comerciales entre ambos países. Mientras ejercía sus funciones, además, seguía en la prensa temas centrales de las relaciones entre Argentina con Brasil y con Chile. ${ }^{13}$

Las divergencias entre las actitudes se ven expresadas en los registros de escritura que estas dos figuras generaron sobre sus etapas como diplomáticos ante Estados Unidos: Quesada escribió los volúmenes titulados Recuerdos de mi vida diplomática. Misión en Estados Unidos y Los Estados Unidos y la América del Sur. Los yankees pintados por sí mismos, en los que predominan el tono de confidencia literaria o memoria, en un caso, y la crítica mordaz, en otro; Zeballos, en cambio, generó un grueso volumen de estudio sistemático sobre las políticas comerciales y el desarrollo agrícola. ${ }^{14}$

Estos indicios sugieren que en el transcurso de estos años podían desplegarse diferentes formas de ser diplomático argentino en los Estados Unidos. Entonces, ¿qué se esperaba de estos representantes?, ¿qué funciones debían ejercer?, ¿qué instrucciones recibían del gobierno argentino?, ¿qué materiales se les solicitaba que generaran en tanto miembros del servicio exterior? Son todos interrogantes que parecen no haber tenido respuestas unívocas.

De hecho, al iniciar con sus responsabilidades, García Mérou dio cuenta del estado de situación y reflexionó sobre el rol de los diplomáticos en Estados Unidos. Por un lado, no dudaba en destacar a una estirpe honorable y se refería a "mis distinguidos antecesores los Ministros Sarmiento, García,

11 Ibíd., pp. 153-154.

12 Pueden consultarse al respecto: Scarfi, J.P., "La emergencia de un imaginario latinoamericanista y antiestadounidense del orden hemisférico: de la Unión Panamericana a la Unión Latinoamericana (1880-1913)”, Revista Complutense de Historia de América, vol. 39, 2013; Follari, R., "Aspectos de la política de los Estados Unidos en la correspondencia diplomática de Vicente G. Quesada”, en Nuestra Historia. Revista de Historia de Occidente, núm. 4142, 1994, pp. 81-104.

13 Sobre Estanislao Zeballos puede verse Etchepareborda, R., Zeballos y la política exterior argentina.

14 Se trata de Zeballos, E., La concurrencia universal y la agricultura en ambas Américas. 
Domínguez, Quesada, Zeballos, etc.”. ${ }^{15}$ Pero, por otra parte, a la vez que se inscribía en un linaje de antecesores ilustres, dejaba claro que las tareas diplomáticas no siempre se ejercían con el compromiso y la sistematicidad que merecían.

En la última dirección, no dudaba en lanzar críticas severas a los diplomáticos argentinos afincados en varios destinos. En los informes y cartas consulares se pueden rastrear numerosas quejas referidas, por ejemplo, a secretarios de legación que residían en Estados Unidos y no hablaban en inglés — hecho que generaba problemas de comunicación constantes-, observaciones sobre la falta de integridad de representantes argentinos que no concurrían a eventos de relevancia internacional o tomaban licencias prolongadas para realizar viajes personales. En sintonía con estas observaciones, y haciendo foco en la representación argentina en Brasil, en una carta a Roca puntualizaba:

con este sistema Ud. comprenderá que no es fácil abrirse camino en ningún país y desgraciadamente este es el que se ha seguido aquí y en otras partes, más de una vez. Así se hicieron detestar Arroyo y su mujer, en el Brasil, porque no hablaban de los fluminenses sino como macacos y otras lindezas igualmente halagadoras para los aludidos, lo que motivó que todo el mundo me adorara cuando llegué a sustituirlo. ${ }^{16}$

En el mismo sentido, dejaba claro en correspondencia no oficial que había logrado hacerse con una reputación en un país en el que los anteriores representantes no siempre se habían lucido:

me complazco en comunicarle que mi familia y yo hemos sido recibidos con la mayor simpatía, y que mi conducta seria, modesta, circunspecta, sin duda por el contraste que formaba con la farsa teatral y de exhibicionismo de alguno de mis antecesores, me ha conquistado la amistad de la más alta sociedad de esta capital eminentemente aristocrática, así como el respeto y la consideración de círculo oficial. ${ }^{17}$

Con el diagnóstico general respecto de los descalabros que algunos diplomáticos generaban en los países en los que se instalaban, García Mérou

15 Carta-informe de Martín García Mérou a Amancio Alcorta, Washington, 21/04/1897. Archivo Histórico de Cancillería Argentina, Serie Misiones al Exterior, Caja AH 116.

16 Carta de Martín García Mérou a Julio Argentino Roca, Presidente de la República, Washington, 17/12/1898. Fondo Documental del Museo Roca.

17 Carta de Martín García Mérou a Ernesto Torquinst, Washington, 29/07/1897. Archivo Histórico de Cancillería Argentina, Serie Misiones al Exterior, Caja AH 117. 
se propuso llevar adelante una gestión que marcara una diferencia. Con este objetivo, emprendió - como se ve en las siguientes secciones- ciertas tareas ligadas al acopio de información, la generación de conocimientos y el fomento de la articulación entre Argentina y Estados Unidos.

Para llevar a buen puerto estas tareas, solicitaba con insistencia mayores empleados para la legación. Dejaba claro que no contaba con los fondos necesarios para poder contar con un segundo secretario, un tipógrafo o un traductor; destacaba que la vida diplomática era por definición comedida, pero que lo era más en Washington. En este sentido, le señalaba a Amancio Alcorta, ante el pedido de fondos extra: "Como Ud. sabe y puede verlo en las comunicaciones de todos mis antecesores de esta Legación, desde nuestro ilustre estadista Sarmiento hasta el señor Zeballos, la vida en Washington es excesivamente cara y los sueldos alcanzan solo para llevar una vida decorosa pero modesta". ${ }^{18}$

Comentaba, además, al Ministro de Relaciones Exteriores y Culto, y a sus amigos y confidentes - entre los que se destaca su hermano Enriqueque él mismo debía cubrir con sus ingresos desde los trajes que vestía para asistir a eventos, reuniones y banquetes hasta los honorarios de los secretarios y copistas de la legación. Cubría también con su estipendio otros gastos: compraba, por ejemplo, parte de la papelería que usaba en la legación, los muebles que necesitaba para las casas que habitaba como representante y libros sobre Argentina que regalaba a los interesados en el país.

Las tareas que realizaba no eran desde su perspectiva del todo reconocidas. Ante las preguntas que le hace un diputado, por ejemplo, le responde que él ya había enviado información que le solicita al Ministro de Relaciones Exteriores y le sugiere que consulte los informes que redactaba regularmente: "es bueno que los miembros del Congreso hagan investigaciones de esta especie, para que se destruya la leyenda de la inutilidad y de haraganería que reputa el Cuerpo Diplomático argentino bajo una capa de descrédito difícil de levantar". ${ }^{19}$

Al señalar los esfuerzos que hacía en la legación, por un lado, como se destacó, criticaba a sus predecesores y a algunos de sus contemporáneos, pero también las actitudes de los hombres de Estado argentinos. De acuerdo a sus amargos balances, reinaba el desinterés general por lo que los enviados

18 Carta de Martín García Mérou a Amancio Alcorta. Washington, 09/06/1897. Archivo Histórico de Cancillería Argentina, Serie Misiones al Exterior, Caja AH 116.

19 Carta de Martín García Mérou a Eleodoro Lobos, Washington, 13/03/1897. Archivo Histórico de Cancillería Argentina, Serie Misiones al Exterior, Caja AH 117. 
a legaciones informaban a Buenos Aires desde destinos con los que la Argentina no mantenía sólidas relaciones comerciales. ${ }^{20}$

En carta privada, resumía esta actitud de los hombres de la política con las siguientes palabras:

desde luego debo advertirle que nuestro Gobierno, siguiendo una práctica constante, se ha escusado, no solo en enviarme instrucciones precisas a propósito de la nueva política fiscal inaugurada por la Administración Mac Kinley, sino que tampoco se ha dignado hacerme saber cuáles son sus ideas en estas materias tan importantes y cuáles los planes de su acción financiera futura en lo que se relaciona con el mantenimiento y el incremento de nuestro intercambio con los Estados Unidos. La orden de nuestra Cancillería se limita a decir 'haga Ud. gestiones y en caso de que ellas no tengan resultado amenace con represalias', y eso ofrece muy poco margen para entrar en arreglos ventajosos y recíprocos. ${ }^{21}$

En la misma carta destaca que generalmente recibe aprobaciones, aunque "ello está muy lejos de ser lo que yo deseo, que no son voces de elogio, sino ideas, planes, concepciones que ayuden a mi labor por mejor decir, que me pongan en situación de hacer algo útil, ventajoso para nuestro país y favorable para nuestros intereses comerciales”.

García Mérou consideró cuatro pilares centrales para desplegar servicios provechosos para la nación que representaba: fondos, una reorganización del personal de la legación, instrucciones precisas de su gobierno y acceso a materiales con información sobre la Argentina. Sin embargo, no todos los contemporáneos compartían esta mirada sobre la diplomacia y su ejercicio.

Tal es así que, por ejemplo, entre las dos etapas de su misión hubo un breve tiempo en el que, mientras él ocupaba el cargo de Ministro de Agricultura en Argentina, Eduardo Wilde ocupó su puesto en la legación de Estados Unidos y México. En ese breve período, Wilde suspendió de manera total las tareas que García Mérou llevaba adelante sin descanso -las mismas se puntualizan en las secciones siguientes-. Su forma de ejercer el puesto diplomático y de moverse en sociedad a partir del mismo, tuvo otras manifestaciones. En general, Wilde vivía la experiencia de ser diplomático con un tono poco solemne y desenfadado. En una carta a Amancio Alcorta escrita

20 Pueden consultarse: Sheinin, D., "Una paradoja comercial-cultural: la Argentina, España y Estados Unidos en la época de la guerra hispano-americana”, en Trabajos y Comunicaciones, número 26-27, 2000-2001, pp. 187-209.

21 Esta cita y la siguiente se encuentran en Carta de Martín García Mérou a Ernesto Torquinst, Washington, 29/07/1897. Archivo Histórico de Cancillería Argentina, Serie Misiones al Exterior, Caja AH 117. 
en 1901, de hecho, desacredita los pedidos que llevaba haciendo García Mérou desde 1896. Señala que no es necesario hacer una reorganización de la legación de forma urgente - tópico central en las cartas oficiales de García Mérou-. Destaca que no se necesitan más fondos y que solamente hay que administrarlos de otras formas para obtener mejores resultados, sin mayores precisiones.

En el mismo sentido, Wilde señala que no se necesitan más empleados para cumplir con las tareas administrativas: "yo no he pedido jamás a nadie un segundo secretario, pero he pedido y pido con insistencia una partida para pagar un empleado permanente, del país, o conocer del país por haber vivido largo tiempo en él”. ${ }^{22}$ En este punto, más que una idea de administración eficiente y efectiva para la legación, sus consideraciones se vinculan más directamente con la idea de que un diplomático debe tener una especie de guía nativo para moverse en la sociedad que lo acoge.

El único punto de coincidencia de Wilde con García Mérou tuvo que ver con la necesidad de sistematizar la publicación de resultados de las legaciones; al respecto considera que es "indispensable que el ministerio tenga un boletín en que se publique diaria o semanalmente el rendimiento publicable de los informes de los ministros diplomáticos y cónsules (...) la publicación estimula y obliga; ella induce a los Ministros y cónsules estudiar el país en que están”.

Las apreciaciones de Wilde rematan en una sentencia: en la diplomacia puede ser lo mismo "hacer que no hacer", o "trabajar que pasarse la gran vida en visitas tontas, saludos ridículos y conversaciones baladíes”; ${ }^{23}$ estas afirmaciones refuerzan las apreciaciones que García Mérou expresaba sobre algunos de sus colegas.

En suma, en las observaciones de Eduardo Wilde no aparece una definición de contornos claros de qué debería hacer un diplomático a lo largo de sus días o de qué demandas recibe del gobierno argentino. En este sentido, se encargaba de dejar claro que él no vestía el traje de funcionario: "yo no soy diplomático, a pesar de la opinión de usted (...) cualquiera puede ser ministro diplomático, pues ello equivale a enterrarse y cualquiera es bueno para enterrar, o bien un ministro puede volverse demente sin que el país se aperciba, porque nada de lo que atañe a su persona moral se exterioriza”. Es esta idea de la invisibilidad potencial de los diplomáticos -aunque ponderada con diferentes modulaciones- la que lo acerca a alguno de los diagnósticos que García Mérou expresaba.

22 Wilde, E., Cosas mías y ajenas, p. 75.

23 Esta cita textual y la siguiente se aprecian en Wilde, E., Cosas mías y ajenas, p. 76. 
Cabe señalar, por último, que Wilde ocupaba el cargo diplomático casi como un castigo, ya que su nombre constantemente se ponía en cuestión en Argentina a raíz de varios sucesos de la década de $1890 .{ }^{24}$ En este sentido, parecía más preocupado por ver en qué forma su estancia en Washington podía permitirle separarse de esos rumores y limpiar su reputación, que por atender los beneficios del país tal como los entendía García Mérou.

Las diferentes formas de entender y ejercer el cargo pueden verse también en los circuitos que García Mérou y Wilde transitaban durante los años de sus servicios: más ligados a la vida pública y el ocio en el caso de Wilde; más cercanos a la vida cultural e intelectual en el caso de García Mérou; estas distintas opciones se hacían eco en cómo las publicaciones de Buenos Aires y Washington cubrían las actividades que ellos y sus esposas realizaban en la legación. Mientras que las noticias vinculadas con los García Mérou cubren la participación en eventos, conferencias, reuniones internacionales, las de los Wilde son seguidas en términos de sociabilidad, hoteles y casas que ocupan, vestimentas que portan y espectáculos a los que acuden. ${ }^{25}$

En suma, ser diplomático argentino en Estados Unidos podía ser varias cosas en el pasaje del siglo XIX al XX. A juzgar por los cuatro casos mencionados (Vicente Quesada, Estanislao Zeballos, Eduardo Wilde y el propio García Mérou), ocupar el cargo no respondía a un solo tipo de perfil o función.

\section{MOSTRAR, CONTAR Y DESCRIBIR ARGENTINA EN EL PAÍS DEL NORTE}

Una de las preocupaciones sostenidas por García Mérou a lo largo de sus años en Washington fue ver las formas en las que se podía dar información sobre la Argentina en Estados Unidos. Sus acciones en este sentido operaron en varios frentes: desde ya, intentó contar con materiales de circulación a nivel diplomático y de presentar libros monumentales junto a productos autóctonos en las ferias y exposiciones; también se ocupó de ver las formas de brindar datos concretos a todos aquellos ciudadanos norteamericanos que recurrían a la legación y solicitaban información sobre aspectos disímiles, entre los que se cuentan: el mercado de tierras, la educación, las estadísticas comerciales, entre otros. De este modo, contar con libros, mapas, folletos y

24 Para detalles sobre la trayectoria de Eduardo Wilde y los sucesos de la década de 1890, véase Bruno, P., Pioneros culturales de la Argentina. Biografías de una época, 1860-1910, pp. 19-54.

25 Cfr. Pepper, Ch., Every Day Life in Washington, pp. 240, 241, 245. 
estadísticas para poner a disposición de maestras, "chacareros" —así son denominados en la correspondencia-, inversores y comerciantes que le enviaban consultas sobre el país - según comenta en varias ocasiones, recibía un promedio de 500 consultas por mes, que responde personalmentemuestra su interés por difundir la realidad del país y mostrar sus potencialidades ante los norteamericanos. Este interés en "mostrar Argentina” operó como un vector de sus tareas y no siempre fue acompañado por las decisiones del Ministerio de Relaciones y Culto Argentino. ${ }^{26}$

Uno de los frentes que García Mérou atendió fue el que presentaban las ferias, los eventos y las exposiciones internacionales. Como es sabido, luego de la inaugural Exposición Universal de Londres de 1851, las distintas ciudades que oficiaron de anfitrionas de exposiciones establecieron una suerte de competencia a la hora de mejorar las dinámicas de muestra y celebración. Los gobiernos de las naciones participantes se ocupaban de acondicionar los pabellones, seleccionar los productos a exponer y reunir el material visual y libresco que los acompañaba.

Las exposiciones no hicieron más que ampliar sus objetivos, mejorar sus infraestructuras y consolidar formatos que fueron reactualizados en cada oportunidad. Dado que el lugar geográfico en el que se realizaba cada uno de estos eventos se convertía en un polo de atracción para el mundo, los gobiernos y otros organizadores comenzaron a plantear la necesidad de que a su alrededor se montaran eventos paralelos y complementarios: muestras artísticas, congresos o reuniones científicas y educativas, y reuniones de carácter internacional en que se discutían asuntos geopolíticos de distinto alcance. ${ }^{27}$

De este modo, ciencia, arte, naturaleza, producción y geopolítica convivían a la hora de vehiculizar ideas de nación, progreso, modernidad y competencia entre naciones. Las exposiciones no solamente eran escenarios para pensar y proyectar ideas de nación; también, y en consonancia con ello, oficiaban como arenas de enfrentamientos simbólicos en varios niveles del mapa mundial. Qué mostrar y cómo hacerlo eran preocupaciones que iban

26 Durante las estancias de Martín García Mérou en Estados Unidos ocuparon la cartera de Relaciones Exteriores y Culto: Amancio Alcorta (enero de 1895-diciembre de 1899); Felipe Yofre (interino entre diciembre de 1899 y abril de 1900); Amancio Alcorta (abril de 1900mayo de 1902); Joaquín V. González (interino entre mayo y agosto de 1902); Luis María Drago (agosto de 1902 -julio de 1903); Joaquín V. González (interino entre julio y septiembre de 1903): José A. Terry (septiembre de 1903-octubre de 1904).

27 Canogar, D., Ciudades efímeras: exposiciones universales, espectáculo y tecnología. 
de la mano para los gobiernos de las jóvenes naciones latinoamericanas en formación. ${ }^{28}$

Ambas preguntas — qué y cómo exhibir- eran engañosamente sencillas. Estas nociones calaron fuertemente en las preocupaciones de Martín García Mérou a lo largo de sus años de servicio en Norteamérica, que coincidieron con los años de consolidación de las exposiciones y ferias internacionales con sede en Estados Unidos. ${ }^{29}$ Por lo menos en tres contextos se subrayaron estas preocupaciones respecto de cómo se mostraba la Argentina ante el mundo.

El primero de ellos es el de la inauguración del Museo Comercial de Filadelfia, abierto a instancias de William P. Wilson en 1897. La idea de montar un museo comercial y exponer productos de todas las naciones había surgido en el marco de la Exposición de Chicago de 1893. Varios organizadores del evento coincidieron en los beneficios que podía tener mantener el espíritu de la exposición en un predio cerrado y de trasladar los productos desde la exposición a un museo. ${ }^{30}$ En los materiales institucionales generados por el museo se proyecta una mirada clara respecto de Argentina: se trataba de un país considerado un potencial competidor comercial de Estados Unidos a nivel mundial. ${ }^{31}$ García Mérou visitó el museo unos meses después de llegar a Washington y compartió esta mirada. Se encargó de dar cuenta de varios puntos al respecto a Amancio Alcorta, Ministro de Relaciones Exteriores y Culto. Entre otras cuestiones, le comentó que había realizado el viaje para revisar "el estado de la parte consagrada a la exhibición de productos de la República Argentina” y le confesaba: "Ud. sabe cuánto me interesa todo lo que se refiere al desenvolvimiento económico de nuestro país, y el celo e interés con que estudio todo lo que puede fomentar nuestro comercio y dar facilidades a la salida de los géneros de nuestra vasta producción. En la época actual, me parece que es uno de los fines principales de la diplomacia". ${ }^{32}$

Pese a la falta de apoyo del gobierno argentino para que García Mérou concurra al museo -insistentemente solicitó fondos para realizar la excursión antes de partir-, él mismo tomó como responsabilidad visitarlo. Al

28 Al respecto pueden consultarse: Di Liscia, M. y Lluch A. (eds.), Argentina en exposición: ferias y exposiciones durante los siglos XIX y XX; González Stephan, B. y J. Andermann, Galerías del progreso: Museos, exposiciones y cultura visual en América Latina; Uslenghi, A., Latin America at Fin-de-Siècle Universal Exhibitions. Modern Cultures of Visuality.

29 Rydell, R., All the World's a Fair. Visions of Empire at American International Expositions, 1876-1916.

30 Véase Conn, S., Museums and American Intellectual Life, 1876-1926, capítulo 4.

31 Cfr. Commerce of Latin American. A Brief Statistical Review.

32 Carta de Martín García Mérou a Amancio Alcorta, Washington, 02/12/1896. Archivo Histórico de Cancillería Argentina, Serie Misiones al Exterior, Caja AH 116. 
regreso de su viaje, encontró en Ernesto Torquinst un interlocutor; le señalaba la necesidad de enviar nuevas muestras de productos por estar deteriorados algunos de ellos. Interpelaba, así, a un particular ante la falta de respuestas oficiales. García Mérou insistía al Ministro Amancio Alcorta y a varios diputados respecto de la importancia del Museo Comercial de Filadelfia como gran vitrina espectacular para mostrarle al mundo los productos potencialmente competitivos de Argentina. Su mirada sobre la institución y su rol no parece en general exagerada, dado que el museo se convirtió en una referencia central para pensar las relaciones comerciales entre las Américas en los siguientes años, tal como quedó manifestado en la II Conferencia Panamericana, realizada en México; allí representantes de distintas naciones americanas bregaron por la conveniencia de renovar el museo y sus colecciones y de nuclear en él información estadística oficial para propiciar los intercambios mercantiles entre las Américas. ${ }^{33}$

La visita que García Mérou realizó al Museo Comercial de Filadelfia, en el que pronunció un discurso en inglés frente a las autoridades, ${ }^{34}$ fue cuidadosamente informada al ministerio pertinente; y él finalmente consiguió el envío de una modesta suma extra para balancear los gastos que había absorbido. Sin embargo, en la correspondencia contemporánea a estos hechos, García Mérou insistía en la falta de atención que le otorgaban a sus informes y sugerencias - entre ellas se destaca una referida a la necesidad de enviar muestras de ónix al museo para darle visibilidad al producto. ${ }^{35}$

Una preocupación similar respecto de cómo se mostraba —o se podía mostrar- la Argentina fue sostenida por García Mérou en un segundo contexto: en torno a la organización y realización de la Exposición de Búfalo de 1901. Cuando ésta se realizaba, él había sido nombrado Ministro de Agricultura en Argentina. Al saber cómo había quedado montado el predio de la nación sostuvo que la presencia del país era "modesta y doméstica" en relación a otras. Las publicaciones de Buenos Aires constataban esta apreciación, La Ilustración Argentina se ocupaba de celebrar el evento: "el feliz pensamiento de iniciar la Gran Exposición Pan-Americana (...) dedicada exclusivamente a las naciones de las Tres Américas, ha hecho vibrar nota armoniosa en estos países independientes de América”, y celebraba la oportunidad de "estrechar más las relaciones sociales y comerciales de las repúblicas, estados y territorios de que se componen la América del Norte, del

33 Véase al respecto David Pletcher, Diplomacy of Trade and Investment: American Economic Expansion in the Hemisphere, 1865-1900.

34 Puede verse el borrador del discurso en Archivo Histórico de Cancillería Argentina, Serie Misiones al Exterior, Caja AH 117.

35 Carta de Martín García Mérou a Amancio Alcorta, Washington, 02/12/1896. Archivo Histórico de Cancillería Argentina, Serie Misiones al Exterior, Caja AH 116. 
Centro y del Sur”; ${ }^{36}$ pero realizaba escasos comentarios sobre la exposición argentina y cubría esa información con fotografías. En sintonía con las apreciaciones de García Mérou, la revista Caras y Caretas señalaba:

no haciendo gala de derroche ni de lujo, como en la de París, figura la República Argentina en la Exposición de Búfalo inaugurada el 1 de mayo del corriente año. Tampoco era necesario más de lo que ha conseguido realizarse, para que nuestra sección, aunque modesta, cumpliese perfectamente con su propósito de presentar un muestrario de sus riquezas naturales y de sus progresos. Tal como está basta para que la Argentina no pase inadvertida en el gran certamen, y pueda ser estudiada en varios de sus aspectos, especialmente en aquellos más dignos de llamar la atención de los capitalistas e industriales norteamericanos en busca siempre de lugares nuevos donde las iniciativas yankees puedan encontrar terreno propicio. ${ }^{37}$

Dado que García Mérou se encontraba en Argentina durante la exposición, lamentaba en su correspondencia que Eduardo Wilde no hubiese prestado la suficiente atención al montaje del stand argentino ni respondido las cartas que le enviaba insistentemente Buchanan, representante de Estados Unidos en Argentina y coordinador general de la muestra. ${ }^{38}$ De hecho, años después de la realización de la exhibición en Búfalo, en carta de 1904, destacaba que la participación de Argentina en esa exposición había tenido motivos diplomáticos que no habían sido lo suficientemente atendidos: "se trataba de complacer a su Director, el Señor Buchanan, que había actuado como árbitro en nuestros pleitos internacionales". ${ }^{39}$

Ya casi al final de su estadía en Washington, y luego de constatar la falta de sostén de los gobiernos argentinos para representar al país en las exposiciones internacionales, García Mérou alertaba por tercera vez sobre los problemas que podían manifestarse a la hora de sumarse a la exposición de Saint Louis. Le señala al respecto a José V. Hernández, que ansiaba una designación para ser representante comisario:

36 La Ilustración Sud-Americana, Periódico Ilustrado de las Repúblicas Sudamericanas, núm. 193, 15 de enero de 1901, pp. 7 y 10.

37 “La Argentina en la Exposición de Búfalo", en Caras y Caretas, 10 de agosto de 1901, p. 35.

38 Cartas de William J. Buchanan a Martín García Mérou, Búfalo, 08/06/1900, 11/06/1900, 16/06/100. Instituto Bibliográfico “Antonio Zinny”, Fondo Martín García Mérou, Caja 3.

39 William Buchanan fue representante diplomático norteamericano en Argentina entre 1894 y 1899; había sido convocado como tercer árbitro para la resolución de la línea limítrofe Puna de Atacama y tuvo un desempeño diplomático destacado por sus compatriotas y algunos hombres de la política argentina durante sus años en Buenos Aires. Véase, Courtney Letts de Espil, La segunda presidencia de Roca vista por los diplomáticos norteamericanos. 
no conozco misión más difícil, más desairada e ingrata que la que le va a tocar en suerte desempeñar. Mi opinión ha siempre sido que no debimos jamás concurrir al mencionado certamen. La suma votada es completamente deficiente, pero aun si ella resulta tirada a la calle, pues no tendremos ventaja alguna de su inversión. Con ese dinero y dado el poco tiempo que falta, así como nuestras notorias incapacidades para organizar estas cosas de una manera conveniente, la exposición argentina resultará pobre, mezquina y altamente ridícula. Es estas cuestiones de proceder en grande o no proceder. Si estábamos resueltos a derrochar una suma que nos hace falta para otras cosas, debimos hacer una exposición completa, mostrando los recursos y la grandeza de nuestro país. Pero venir a poner en fila montones de lana sucia, algunos cueros secos y tarros con muestras de trigo, así como algunos especímenes de nuestro arte pictórico que todavía se encuentra en pañales, a pesar de las ilusiones de nuestro entusiasta Director del Museo de pinturas que llegará pronto a los Estados Unidos cargado de bocetos y telas —me parece sencillamente deplorable e inútil_... No dude Ud. que nuestra exposición en Saint Louis no dará motivos sino para críticas fundadas y para avergonzarnos a nosotros mismos. ${ }^{40}$

La extensión de la cita textual permite apreciar los tópicos que acompasaron las apreciaciones de García Mérou a lo largo de sus años norteamericanos respecto de los límites para que Argentina se pudiera mostrar como una nación consolidada: falta de presupuesto, incapacidad en la organización, desinterés, escasez de productos atractivos para mostrar a las otras naciones, un arte argentino en gestación, eran indicadores de la falta de atención que, al menos al contexto norteamericano - $\mathrm{y}$ al mismo como potencial vitrina para el mundo-, se le daba desde el país.

En suma, el balance general del rol de la Argentina en estas instancias de exposición más allá de sus fronteras no conformaba a García Mérou, quien compartía estas opiniones con varios de sus contemporáneos. Pero no fue solamente este diagnóstico desalentador lo que marcó sus actividades diplomáticas en Estados Unidos. A lo largo de sus estancias García Mérou encaró con sistematicidad una tarea para tratar de revertir varios de los escollos que encontró durante sus gestiones.

Si la Argentina no estaba a la altura de ser mostrada en exhibiciones debía, por lo menos, ser contada y descripta ante quienes tuvieran interés en conocer al país a través de páginas impresas. Con este objetivo, García Mérou realizó numerosos pedidos de envíos de materiales a distintas personas del gobierno argentino, encontrando, la mayor parte de las veces, falta de respuesta, o, en el mejor de los casos envíos de materiales insuficientes.

40 Carta de Martín García Mérou a José V. Hernández, Washington, 04/01/1904. Archivo Histórico de Cancillería Argentina, Serie Misiones al Exterior, Libro 22. 
Tampoco en este frente parecían estar disponibles los recursos. De hecho, García Mérou notó muy tempranamente que cuando diplomáticos de todo el mundo y políticos o periodistas norteamericanos le solicitaban información sobre Argentina, tenía que recomendarles no pocas veces lecturas de libros escritos por visitantes y no por locales. Ante la ausencia de referencias y de producciones disponibles para su circulación en lengua inglesa, se propuso dar forma a un manual (handbook) general sobre Argentina.

La empresa le tomó varios años de trabajo — comenzó a acopiar información en 1896 - en los que, según se puede seguir en su correspondencia: solicitó personalmente a libreros de Argentina, Uruguay, Chile y Francia el envío de libros que compró con sus propios fondos, escribió a amigos que había hecho durante sus años de ejercicio diplomático en Colombia, Paraguay y España para solicitar materiales y datos, pidió a los ministros argentinos cifras y precisiones para completar información. Según narra, este material fue por él canalizado a la Oficina de las Repúblicas Americanas para el armado del volumen Argentine Republic, que se publicó en 1903. García Mérou, además de recolectar los materiales, corrigió los textos en inglés y mejoró las piezas cartográficas que acompañan el volumen. ${ }^{41}$

Esta intención de contar con información actualizada y detallada para ofrecer a los interesados norteamericanos fue una de las tareas que mantuvo sostenidamente. Este trabajo tenía, además, una trama del revés: se ocupó de generar información y de generar conocimientos para que desde Argentina se conociera de la manera más precisa posible a los Estados Unidos - los detalles sobre este punto se encuentran en la sección siguiente-. Desde el envío de su primer informe anual a Amancio Alcorta, escrito en Washington, 21 de abril de 1897, dejó sentado que consideraba que parte de sus funciones tenían que ver con "estudiar detenidamente la marcha de esta gran nación, trasmitiendo numerosos informes a ese Ministerio a propósito de interesantes cuestiones económicas, sociales y diplomáticas”. ${ }^{42}$

En este sentido, una de las primeras cuestiones que lo mantuvo ocupado fue la discusión sobre las tarifas que se aplicaban a las lanas en Norteamérica. En Estados Unidos se estaba dando un profundo debate sobre el derecho de este producto, el cual se inscribía en un clima general de proteccionismo propiciado durante la presidencia de William McKinley (1897-1901). ${ }^{43}$

41 International Bureau of The American Republics (compiled by), Argentina Republic. A geographical sketch with special reference to economic conditions, actual development, and prospects of future growth

42 Carta-informe de Martín García Mérou a Amancio Alcorta, Washington, 21/04/1897. Archivo Histórico de Cancillería Argentina, Serie Misiones al Exterior, Caja AH 116.

43 Carta de Martín García Mérou a Amancio Alcorta, Washington, 04/11/1896. Archivo Histórico de Cancillería Argentina, Serie Misiones al Exterior, Caja AH 116. 
García Mérou advirtió insistentemente sobre el perjuicio que podían sufrir los productos argentinos en este contexto y acerca de la imposibilidad de firmar un tratado de reciprocidad. ${ }^{44}$ Los hombres de Estado argentinos no respondieron a estas inquietudes y, como se citó ya, García Mérou se refería a la falta de instrucciones como "una práctica constante". ${ }^{45}$

Mientras se discutían los aranceles de la lana, en los primeros meses de su estadía en Washington, García Mérou recibió una carta de la Oficina Comercial de las Repúblicas Americanas en la que se señalaba una deuda de $1.210,00$ dólares. ${ }^{46}$ En el marco de la I Conferencia Panamericana varias naciones, entre las que se contaba la Argentina, habían firmado el compromiso de sostener a esta institución; la función de la misma era generar y compilar información (estadísticas, legislación, reglamentaciones) para propiciar relaciones comerciales de acuerdo a los intereses de cada país. Las cuotas argentinas se habían dejado de pagar desde 1891 y solamente se volvieron a pagar en $1898 .{ }^{47}$

Martín García Mérou atribuyó la falta de pago de estos aranceles a la desidia y a la falta de compromiso con organismos internacionales. En carta al Presidente Julio Argentino Roca de 1898, luego de solicitarle a Amancio Alcorta que la Argentina mantuviera su compromiso de la oficina, García Mérou detalla:

como Ud. sabe, la Oficina de las Repúblicas Americanas se fundó por decisión de los representantes de las naciones que concurrieron a la Conferencia Panamericana reunida en Washington en 1889/90, con excepción de Chile que se negó a tomar parte en su creación. Cada gobierno debe contribuir con una cuota anual.

Le alertaba además a Julio Argentino Roca que la fama de los representantes argentinos en Estados Unidos no era la mejor, y que restablecer el pago de las cuotas era una oportunidad para redimirse en este frente: "Quesada no concurrió al Congreso Pan-Americano donde fuimos representados por Quintana y Sáenz Peña que han dejado aquí un recuerdo deplorable,

44 Cartas de Martín García Mérou a Amancio Alcorta, Washington, 21/11/1896 y 14/12/1896. Archivo Histórico de Cancillería Argentina, Serie Misiones al Exterior, Caja AH 116.

45 Carta de Martín García Mérou a Ernesto Torquinst, Washington, 29/07/1897. Archivo Histórico de Cancillería Argentina, Serie Misiones al Exterior, Caja AH 117.

46 The Commercial Bureau of the American Republics/Oficina Comercial de las Repúblicas Americanas se creó en 1890 a instancias de lo acordado en la I Conferencia Panamericana. En 1902 este organismo cambió de denominación y se llamó International Bureau of the American Republics/Oficina Internacional de las Repúblicas Americanas. En la IV Conferencia Panamericana el nombre pasó a ser Pan American Union/Unión Panamericana.

47 Sanchís Moreno, J., Historia diplomática argentina, p. 157. 
pues no se ocuparon sino de resentirse por nimiedades y de hacer cuestión de estado, por los más fútiles y mujeriles detalles de etiqueta". ${ }^{48}$ Le comentaba, además, que la oficina se había reorganizado, y le atribuía a Vicente Quesada la idea errónea de que participar activamente en la institución no aportaba nada al país.

En suma, su intención era dejar sentado frente a Julio A. Roca y Amancio Alcorta que participar en el nuevo entramado de relaciones surgido a la luz de la I Conferencia Panamericana era central para posicionar geopolítica y culturalmente a la Argentina. A instancias de García Mérou las relaciones fueron establecidas y este hecho facilitó la publicación del ya mencionado manual titulado Argentine Republic en 1903.

Estas aproximaciones y esfuerzos de García Mérou como representante argentino en Washington, sin embargo, no se tradujeron en la ampliación de relaciones comerciales entre ambos países, en un contexto que, como es sabido, la Argentina estaba atenta a otros zigzagueos a la hora de pensar en sus socios comerciales. ${ }^{49}$ Pese a ello, para García Mérou la asociación estrecha que sugería en los primeros años de su misión entre diplomacia y comercio cambió de signo con el correr de los años y sus observaciones sobre el rol de Estados Unidos en el mundo comenzaron a tener otros acentos. Este desplazamiento no es extraño a la luz de su trayectoria. A lo largo de su itinerario diplomático, García Mérou cumplió varias funciones, fue secretario de Miguel Cané en Colombia y Venezuela, luego permaneció allí como Encargado de Negocios, posteriormente fue designado Secretario de Legación en Madrid y más tarde, Ministro Plenipotenciario en Paraguay, Perú y Brasil. En todas estas geografías escribió informes y libros sobre los países en los que residió. En suma, la mayor parte de su vida estuvo instalado en naciones diferentes que no eran su país natal y convirtió sus residencias en América latina y Estados Unidos en ocasiones para recopilar materiales, investigar las sociedades que lo acogieron y traducir en textos sus experiencias y análisis. Este rasgo diferencial fue percibido en el ambiente porteño atento a las novedades editoriales. Por ejemplo, frente a la publicación de uno de sus últimos libros sobre Estados Unidos, un comentarista de la Revista de Derecho, Historia y Letras observaba: "un buen ejemplo, digno de imitarse, particularmente entre la mayoría de los miembros de nuestro cuerpo diplomático, tan inclinado a la vida contemplativa”. ${ }^{50}$

48 Carta de Martín García Mérou a Julio Argentino Roca, Presidente de la República, Washington, 17 de diciembre de 1898, Fondo Documental del Museo Roca.

49 Véanse McGann, T., Argentina, Estados Unidos y el sistema interamericano, 1880-1914; y Peterson. H., La Argentina y los Estados Unidos, 1810-1914.

50 Revista de Derecho Historia y Letras, vol. 20, 1904, p. 243. 


\section{EL COLOSO AMERICANO: AMENAZA, EXPANSIÓN, ESPEJO}

Las primeras cartas informativas de García Mérou al Ministro de Relaciones Exteriores y Culto luego de su llegada a Estados Unidos dejaban claro que su intención era, como se destacó ya, recopilar la mayor cantidad de información sobre el país con la intención de propiciar acercamientos comerciales entre ambas naciones. Ese propósito inicial se amplió en los años de estadía en el país y ese desplazamiento lo condujo a otro tipo de reflexión sobre la nación del Norte, más dispuesto a analizar las coordenadas culturales, políticas y económicas del país a través del estudio de sus dinámicas, sus tradiciones y sus poblaciones.

La mirada negativa compartida por varios de sus contemporáneos respecto de Estados Unidos era evocada por varios enviados a Estados Unidos y México. Si ya en 1893, hacia el final de su misión diplomática, Vicente Quesada había apuntado "diré lo que pienso a pesar que ello dé grima a los que se creen los primeros entre los primeros; la más poderosa nación del orbe conocido, para la cual todas las demás son inferiores como agrupaciones humanas, como fuerza, como inteligencia", ${ }^{51}$ en 1901, el ya mencionado Eduardo Wilde sentenció en el mismo sentido mientras cumplía funciones en el país del Norte: "no quiero hablarle de la política de este país; le diré sin embargo en fórmula mi pensamiento: no esperan aquí en sus relaciones con el resto del mundo, sin excluir ni la Inglaterra, ni la Rusia, ni la Alemania, otra cosa que sumisión a todo lo que se les antoje hacer. Es inútil su simpatía ni su reciprocidad (como entidad política, se entiende)". ${ }^{52}$

Estas voces dan cuenta de un clima más general de lecturas negativas sobre Estados Unidos que se manifestó desde que se realizó la I Conferencia Panamericana, realizada en Washington en 1889, y se evidenciaron las tensiones entre Norteamérica y algunos países del continente - entre los que se destacó Argentina-. Este estado de opinión y estas miradas se vieron confirmadas y amplificadas poco después con la Guerra entre España y Estados Unidos de 1898.

En este arco temporal (1889-1898), varios intelectuales latinoamericanos expresaron preocupaciones sobre la suerte de sus países desde el momento mismo en que, desde Estados Unidos, se convocó a la conferencia de las Américas. En ella, la nación anfitriona presentó un proyecto para formar una unión aduanera y consolidar el intercambio entre los países del continente (el mismo incluía ítems para homogeneizar pesos, medidas y moneda, formar

51 De Pantoja, Domingo (seudónimo de Vicente Quesada), Los Estados Unidos y la América del Sur. Los yankees pintados por sí mismos, p. 3.

52 Wilde, E., Cosas mías y ajenas, p. 116. 
una corte destinada a arbitrar en conflictos potenciales entre naciones, unificar los impuestos portuarios, entre otros). Este conjunto de medidas apuntaba a consolidar el rol articulador de la nación del Norte como principal árbitro autorizado y priorizar sus objetivos económicos en detrimento de la presencia europea en el continente. ${ }^{53}$

En el contexto del evento, celebrado en la ciudad de Washington, la delegación norteamericana encontró fuertes resistencias a este proyecto en las voces de los representantes de Argentina, Roque Sáenz Peña y Manuel Quintana, y en los de Chile, Emilio C. Varas y José Alfonso. Ambas comitivas rechazaron la propuesta de la unión aduanera y otra más moderada, que presentaba como posibilidad la concreción de acuerdos entre países (bilaterales o multilaterales) para potenciar un espacio de intercambios fluidos, que en el futuro podría funcionar como una zona de libre intercambio. Esta última opción, en cambio, fue aceptada por los representantes de Brasil, Nicaragua, Venezuela, Colombia, México y los anfitriones. Brasil, en cambio, apoyó con énfasis la propuesta del panamericanismo y firmó varios acuerdos bilaterales con Estados Unidos, en una situación bastante caótica, dado que fueron delegados del Imperio los que participaron en las sesiones de la conferencia, mientras que los acuerdos, en cambio, fueron firmados por delegados de la República. ${ }^{54}$

Sin tomar posiciones tajantes, la I Conferencia Panamericana suscitó en García Mérou una serie de reflexiones sobre Brasil y Estados Unidos en el escenario continental americano. Respecto a Brasil, país al que conocía de primera mano y al que había estudiado, varios eran los rasgos contextuales que evaluaba como positivos. ${ }^{55}$ Por un lado, se vio especialmente entusiasmado con la proclamación de la República, en 1889, pues clausuraba la experiencia de un "caso exótico" y perfilaba al país como una nación moderna y pujante en Sudamérica. Por otro, aunque superficialmente se podían trazar analogías entre Brasil y Argentina, las diferencias entre ambos países eran notables desde su perspectiva: Argentina seguía ligada comercial y financieramente a Inglaterra, mientras que, desde las últimas décadas del Imperio, Brasil había planteado una política de gradual aproximación a Es-

53 Entre tantos otros aportes, pueden verse: Raymont, H., Vecinos en conflicto. La historia de las relaciones entre Estados Unidos y Latinoamérica desde Franklin Delano Roosevelt hasta nuestros días; Sheinin, D., Searching for authority: Pan Americanism, diplomacy and politics in United States-Argentine relations, 1910-1930.

54 Puede verse Spyer Dulci, T. M., As Conferências Pan-americanas. 1889-1928. Identidades, União Aduaneira e Arbitragem.

55 Véase García Mérou, M., El Brasil intelectual. Impresiones y notas literarias. 
tados Unidos. ${ }^{56}$ Este escenario le había generado algunas preguntas respecto de cómo se equilibrarían los poderes dentro de las Américas.

Al llegar a Estados Unidos y concentrarse en la observación del país, sus primeras opiniones estuvieron en línea con las voces más pesimistas de varios de sus contemporáneos respecto del país que lo hospedaba. De hecho, al realizar su primera misión en México en 1897, le señalaba a Amancio Alcorta: "como usted sabe, aquella nación se encuentra bajo la influencia directa y en la esfera de atracción del coloso americano; y es útil medir de cuando en cuando los avances que este hacer en su absorción pacífica como el alcance real del prestigio y simpatía de que goza en la nación vecina”. ${ }^{57}$

También al informar sobre la situación de Cuba consideró que las decisiones geopolíticas norteamericanas debían ser vistas como una potencial amenaza, ${ }^{58}$ y destacó "más conveniente para nuestros países, para nuestro provenir y nuestra independencia, que ella (Cuba) continúe como hasta ahora, en vez de ser absorbida por un poder cuya expansión e influencia es la más grande amenaza que deben vislumbrar las naciones sudamericanas en el futuro". ${ }^{59}$

Como se destacó ya, a lo largo de su experiencia diplomática vio la forma en la que Estados Unidos y su rol internacional cambiaron considerablemente. Esos años fueron particularmente intensos en lo que respecta a la consolidación de un repertorio de imágenes vinculadas a los cambios geopolíticos internacionales, que habilitó diálogos entre voces provenientes de la diplomacia, la vida intelectual y artística, y la política, más allá de las fronteras nacionales. Si intelectuales y políticos latinoamericanos habían encontrado un ejemplo y un modelo a seguir en aspectos vinculados con la organización política en las primeras décadas de vida independiente en la nación del norte, en el pasaje del siglo XIX al XX se desplegaron discursos que advirtieron en los Estados Unidos un peligro latente para América Latina. ${ }^{60}$ El equilibrio entre el Viejo y el Nuevo Mundo parecía inclinarse irre-

56 Bruno, P., "Martín García Mérou entre Brasil, Argentina y Estados Unidos. Observaciones para pensar el fin-de-siglo americano", en AA.VV., Gregorio Weinberg: escritos en su honor. Premio Gregorio Weinberg a la Investigación en Historia de la Educación, la Ciencia y la Cultura Latinoamericanas.

57 Cartas de Martín García Mérou a Amancio Alcorta, Washington, 24/08/1897. Archivo Histórico de Cancillería Argentina, Serie Misiones al Exterior, Caja AH 116.

58 Puede consultarse López, C., "Los intelectuales argentinos frente a la independencia cubana de 1898: último bastión imperialista y nuevo status colonial”, en Araucaria. Revista Iberoamericana de Filosofía, Política y Humanidades, núm. 26, 2011, pp. 3-25.

59 Cartas de Martín García Mérou a Amancio Alcorta, Washington, 21/11/1896. Archivo Histórico de Cancillería Argentina, Serie Misiones al Exterior, Caja AH 116.

60 Terán, O., "El primer antiimperialismo latinoamericano", en Id., En busca de la ideología argentina; Bruno, P., "Mamuts vs. hidalgos. Lecturas de Paul Groussac sobre Estados Uni- 
vocablemente hacia el segundo, capitaneado por su Norte. Los atributos y defectos de este nuevo orden cristalizaron en la imagen de Estados Unidos como nación portadora de una fuerza arrolladora, y con ella, en representaciones que se volverían prototípicas, como la de un "mundo yankee" que condensaba todos los vicios del materialismo anglosajón, o el retrato de España como baluarte último y absoluto de la latinidad. En este clima se operó una redefinición de la identidad latinoamericana con un creciente tenor antinorteamericano. ${ }^{61}$

Aunque predominante, esta mirada no fue única. Otras voces se alzaron para enunciar que Estados Unidos podía ser un ejemplo cultural, político y económico para los países latinoamericanos. Entre ellas, se destaca la de García Mérou. ${ }^{62}$ Sus intervenciones al respecto pueden leerse en varios registros: crónicas en los periódicos, informes consulares publicados, y ensayos compilados en Estudios Americanos (1900) y en Apuntes económicos e industriales sobre los Estados Unidos (1905). Allí se detectan dos momentos, uno signado por el calor de la coyuntura en el que todavía no desaparece la idea de Estados Unidos como amenaza potencial, y otro de carácter más reflexivo en el que García Mérou comienza a ponderar positivamente rasgos que considera reivindicables del país del Norte.

El primer momento puede rastrearse en sus participaciones en la prensa. Existe consenso a la hora de señalar que la guerra de 1898 fue un punto de inflexión en los modos periodísticos de cobertura de los conflictos bélicos. De hecho, se ha destacado que la expresión "prensa amarilla" surgió durante el conflicto, y tuvo que ver con el nivel de detalle con que se presentaban sus dramas y crueldades. Más aún, se ha atribuido responsabilidad a los medios de prensa en la declaración misma de la guerra por el presidente McKinley, sobre todo del New York World (comandado por Joseph Pulitzer) y del New York Journal (con William Hearst a la cabeza). ${ }^{63}$ Ya con la guerra desatada, la participación de Estados Unidos estuvo apuntalada por una campaña de

dos y España en el fin-de-siglo”, en A. Pita González y C. Marichal Salinas (comps.) Pensar el antiimperialismo. Ensayos de historia intelectual latinoamericana 1900-1930.

61 Halperin Donghi, T., "España e Hispanoamérica: miradas a través del Atlántico (18251975)", en Id., El espejo de la historia. Problemas argentinos y perspectivas latinoamericanas, 65-110; Díaz Quiñones, A., Sobre los principios. Los intelectuales caribeños y la tradición, capítulo I.

62 Véanse sobre este asunto particular: Auza, N., "Martín García Mérou, un estudioso de la sociedad americana de fines del siglo XIX y comienzos del XX", en Investigaciones y Ensayos, núm. 18, 1975, pp. 311-333; y Bruno, P., "Estados Unidos como caleidoscopio. Ensayo sobre las observaciones de viajeros y diplomáticos del fin de siglo", en Revista Complutense de Historia de América, vol. 39, 2013, pp. 23-38.

63 Campbell, J., Yellow Journalism: Puncturing the Myths, Defining the Legacies. 
prensa sostenida, encabezada por Hearst, que fomentó en la ciudadanía norteamericana un sentimiento de rechazo a España. ${ }^{64}$

El impacto de estas tendencias fue trasnacional. En Buenos Aires las revistas que se ocupaban de la vida diplomática y de los acontecimientos internacionales no contaban con plumas informadas o preparadas para cubrir el conflicto. Para remediar el vacío se instrumentaron varias estrategias. En el caso de las revistas, como La Ilustración Sudamericana ${ }^{65}$-publicación de aparición quincenal especialmente interesada en la vida diplomática e intelectual de las Américas-, por ejemplo, a lo largo de 1898 se mantuvieron tres modalidades para dar cuenta de los cambios que estaban sucediendo a nivel continental. En el contexto mismo de la guerra de 1898, por un lado, se recurrió a dos estrategias para "contar” y "cubrir” la guerra. La primera, y más recurrente, fue publicar fragmentos de libros o relatos de viajes a Estados Unidos y a España que habían tenido lugar en los años inmediatamente anteriores al conflicto bélico. Se encuentran, por ejemplo, fragmentos del viaje a España de Rafael Sánchez Lizardi, ${ }^{66}$ los comentarios de Carlos Lix Klett sobre su gira por Estados Unidos — visitas a universidades, fábricas y otros- ${ }^{67}$ y fragmentos del viaje del español Rafael Puig y Valls por Estados Unidos. ${ }^{68}$ En el mismo sentido, se publicaban textos producidos en los años anteriores que revestían una "actualidad palpitante" para pensar en la guerra, al menos desde la perspectiva de los redactores de La Ilustración Sudamericana. Es el caso de unas páginas de Juan Bautista Alberdi descriptas como "nacidas al calor de la contienda franco-prusiana" que bajo el título "La Guerra Moderna" se publican in extenso ${ }^{69}$ Estos recursos se presentaban como registros anticipatorios del caos, en tanto "preanunciaban" el ascenso norteamericano y la decadencia española, o bien aportaban información para interpretar la guerra en general.

64 Véase Campbell, J., The Spanish-American War: American Wars and the Media in Primary Documents; y Cagni, H., La guerra hispanoamericana y el inicio de la globalización.

65 El nombre completo de la revista es La Ilustración Sud-Americana, Periódico Ilustrado de las Repúblicas Sudamericanas.

66 Sanhueza Lizardi, R., Viaje a España; fragmentos reproducidos en La Ilustración SudAmericana, Periódico Ilustrado de las Repúblicas Sudamericanas, núm. 131, 1 de junio de 1898, p. 210.

67 Se encuentran textos de Lix Klette, por ejemplo, en La Ilustración Sud-Americana, Periódico Ilustrado de las Repúblicas Sudamericanas, núm. 131, 1 de junio de 1898, p. 206; núm. 135, 1 de agosto de 1898, p. 282; núm. 137, 1 de septiembre de 1898, p. 323

68 Puig y Valls, R., Viaje a América: Estados Unidos, Exposición Universal de Chicago, México, Cuba y Puerto Rico; fragmentos reproducidos en La Ilustración Sud-Americana, Periódico Ilustrado de las Repúblicas Sudamericanas, núm. 129, 1 de mayo de 1898, p. 169.

69 La Ilustración Sud-Americana, Periódico Ilustrado de las Repúblicas Sudamericanas, núm. 130, 16 de mayo de 1898, p. 190. 
Por otro lado, La Ilustración Sudamericana optaba por reproducir conferencias de intelectuales en actos públicos a favor de España, como las que se pronunciaron el 2 de mayo en el Teatro de la Victoria y estuvieron a cargo de Paul Groussac y Roque Sáenz Peña; ${ }^{70}$ o la que pronunció Alberto del Solar el 20 de junio en el Ateneo, publicada bajo el título "La Doctrina Monroe y la América Latina". ${ }^{71}$ Como tercer recurso se replicaron notas de prensa de otros países (en ambos casos, en general sin comentarios u observaciones complementarias). ${ }^{72}$

En suma, como mirador, las páginas de La Ilustración Sudamericana mostraban que la guerra entre España y Estados Unidos parecía estar inscripta en las condiciones estructurales de ambas naciones señaladas por testigos oculares, en el caso de los viajeros; o bien, parecía ser inevitable a la luz de textos doctrinarios pensados para otros conflictos. A su vez, cuando se reproducían conferencias no se optaba por sumar comentarios interpretativos. Es decir, en ningún caso se publicaban artículos de información o análisis sobre los sucesos internacionales y sus efectos en sí. Otras opciones fueron utilizadas por otras revistas de corte más erudito.

Así, por ejemplo, puede observarse en las páginas de la Revista de Derecho, Historia y Letras $^{73}$ fundada por el mencionado Estanislao Zeballos y publicada con frecuencia mensual. Esta revista, que hoy es consideraba central para ver cómo se trataban los temas ligados al panamericanismo y a las Conferencias Panamericanas, muestra que fue recién en las primeras décadas del siglo Xx cuando estos asuntos comenzaron a ser tratados en artículos eruditos. En el marco del conflicto bélico de 1898, en cambio, solamente se destaca un breve texto de Julio Carrié que coloca al tono de la

70 Las conferencias se publicaron en folleto: España y Estados Unidos. Función dada en el Teatro de la Victoria el 2 de mayo de 1898 bajo el patrocinio del Club Español de Buenos Aires, a beneficio de la Suscripción Nacional Española. Conferencias de los Señores Dr. Roque Sáenz Peña, Paul Groussac y Dr. José Tarnassi. Prólogo del Dr. Severiano Llorente, Buenos Aires, Compañía General de Billetes de Banco, 1898.

71 Publicada en follero Alberto del Solar, La Doctrina Monroe y la América Latina (Conferencia leída en el Ateneo el 20 de junio de 1898), Buenos Aires, Jacobo Peuser, 1898.

72 Véase Bruno, P., "El escenario internacional en el fin-de-siglo. Un panorama sobre voces de intelectuales y diplomáticos argentinos en revistas y eventos internacionales”, ponencia presentada en las V Jornadas de Relaciones Internacionales FLACSO/Cátedra UNESCO de Desafíos Transnacionales y Gobernabilidad, realizadas el 2 y 3 de noviembre de 2017 en Buenos Aires.

73 Para una caracterización de la Revista de Derecho, Historia y Letras, véase Celada Domínguez, G. y R. Giacalone, "Revista de Derecho, Historia y Letras (1898-1923). Estudio e índice general”, en IUSHISTORIA, núm. 4, 2007 y núm. 5, 2008, edición digital disponible en $<$ www.salvador.edu.ar/juri/reih/index.htm>. 
revista en un giro de carácter coyuntural. ${ }^{74}$ Carrié estaba en Nueva York y en este texto contaba una discusión que se estaba dando en la prensa y entre los políticos sobre el expansionismo norteamericano y la anexión de Filipinas. En el intercambio que reseña entre el New York Times y el New York World, Carrié subraya el debate que se estaba dando entre quienes utilizaban el concepto de "imperialismo" y aquellos que, en cambio, hablaban de "expansión”. La sorpresa del ocasional corresponsal en Nueva York por la discusión ferviente y cotidiana en la prensa de estos tópicos interviene con una tonalidad "fresca" que es muy diferente a la que en general se encuentra en las páginas de la revista. ${ }^{75}$

Pero estas opciones a las que echaban mano las publicaciones interesadas en el escenario internacional no eran del todo aptas para la prensa diaria. En los periódicos la estrategia más común era traducir cables para dar cuenta de lo que sucedía en otras latitudes, pero el conflicto de 1898 parecía demandar otro tipo de información. ${ }^{76}$

En este marco de carencias y necesidades fueron requeridos personajes como García Mérou. Siendo diplomático, entonces, encontró una plataforma original de intervención pública: devino corresponsal de La Nación en suelo norteamericano. La iniciativa del diario fue convocar a "un estadista que es a la par un escritor de raza", para informar sobre el "conflicto hispanoamericano". Sus cartas de "palpitante actualidad", presentadas en columnas que se titulaban "Noticias Americanas" fueron firmadas con el seudónimo Ignotus. El diario apuntaba que "la posición que ocupa dicho caballero en Washington le impide firmar sus trabajos periodísticos". ${ }^{77}$ En consecuencia, las impresiones de García Mérou, ministro plenipotenciario argentino en Estados Unidos, fueron uno de los canales más significativos, y novedosos, con los que el diario fundado por Bartolomé Mitre cubrió la guerra.

Los motivos por los que García Mérou aceptó escribir en la prensa fueron, de acuerdo a sus testimonios, principalmente económicos. ${ }^{78}$ Mientras

74 Julio Carrié, “La cuestión Filipinas y la opinión americana”, Revista de Derecho, Historia y Letras, tomo III, 1899, p. 99.

75 Ibíd., p. 100

76 Buenos Aires fue un foco dinámico de movilización en el marco de los sucesos de 1898; la presencia de una comunidad española significativa numéricamente, operó como caja de resonancia de este clima. Pueden verse: García Sebastiani, M., "España fuera de España. El patriotismo español en la emigración argentina: una aproximación”, Hispania, vol. 73, núm. 244, 2013, pp. 469-500; García, I., “Apoyo a los españoles a la causa de la Cuba española. El caso argentino”, Estudios Sociales, núm. 19, 2000, pp. 85-104.

77 La Nación, Buenos Aires, 03/04/1898.

78 Puede verse, por ejemplo: Carta de Martín García Mérou a Enrique García Mérou, Washington, 16/10/1899. Instituto Bibliográfico “Antonio Zinny”, Fondo Martín García Mérou, Caja 3. 
que en las páginas de la prensa escribía sucesivas entregas sobre la guerra, en el registro de la correspondencia oficial señalaba de hecho que no había mandado informes durante el conflicto "porque es muy difícil formar de ellos una apreciación exacta, deformados, exagerados y falseados como se presentan por las declamaciones e invenciones de la prensa sensacional". ${ }^{79}$ Compartía, en este punto, una idea con sus contemporáneos: la prensa podía ser perniciosa a la hora de formar opinión. ${ }^{80}$ Esta apreciación, en cambio, no le prohibió dar cuenta de sus observaciones sobre la guerra y sus efectos en la política y la sociedad norteamericana.

En su primera entrega, Mérou se encargó de describir una "fiebre bélica que se ha apoderado de este país”, y destacó que los sucesos mantenían en "excitación constante a la opinión pública americana". Sus relatos mostraban cómo una parte del parlamento y de la opinión pública se convertía en "jingoísta”, develando la efectividad de los discursos que colocaban a España como sinónimo de decadencia, mientras ponderaban a Estados Unidos como potencia expansionista. ${ }^{81}$

Entre las notas americanas sobresale una en la que detalla la mencionada evaluación de la prensa y sus protagonistas. En ella, afirma irónicamente "la inventiva fenomenal de los periodistas americanos", gracias a la cual habían logrado movilizar a la opinión pública, "forjando las más fantásticas leyendas y los cuentos más inverosímiles para entretener el ocio de lectores acostumbrados a los terribles condimentos de su prosa sensacional”. Luego de describir toda una serie de industrias surgidas al calor de la guerra - desde la fabricación de juguetes alegóricos hasta la producción de banderas, cintas y botones-, remata:

cuando se ve este entusiasmo ingenuo, este show de patriotismo espectacular, tan propio de esta raza aparentemente fría pero nerviosa e inflamable como pocas, uno comprende que la verdadera causa de la actual guerra no ha sido Cuba ni las pretendidas víctimas de la crueldad castellana, sino el deseo de tener una querella, el empeño de 'jugar a los soldados', de ensayar sus fuerzas que ha invadido de pronto a este coloso y en una ráfaga de locura universal lo ha lanzado sin razón en esta aventura sangrienta”. ${ }^{82}$

79 Carta de Martín García Mérou a Amancio Alcorta Washington, 29/01/1899. Instituto Bibliográfico “Antonio Zinny”, Fondo Martín García Mérou, Caja 3.

80 Véase Bruno, P., "Lecturas de Miguel Cané sobre la función de la prensa en las sociedades modernas”, en Cuadernos Americanos, Nueva época, vol. I, núm. 123, 2008, pp. 113-138.

81 La Nación, Buenos Aires, 24/04/1898.

82 Esta cita y la anterior se pueden ver en La Nación, Buenos Aires, 04/07/1898. 
Este tipo de juicios críticos al presidente William McKinley, envuelto en un "sueño de la política imperial", o sobre un nacionalismo exacerbado y una opinión pública constitutivamente belicista, fue recurrente en las notas enviadas en 1898.

En cambio, una vez finalizada la guerra, se inicia un segundo momento en sus reflexiones sobre Estados Unidos, al ritmo de un clima que él mismo caracteriza como de recuperada "cordura nacional" en la sociedad norteamericana. Tanto en los textos publicados en Estudios Americanos ${ }^{83}$ —varios de ellos basados en datos ya presentes en los materiales de las crónicas de $L a$ Nación-, como en la forma de narrar la guerra en su Historia de la Diplomacia Americana —dos volúmenes publicados en 1904—, ${ }^{84}$ su tono se atemperó y primaron las miradas de carácter optimista sobre Estados Unidos.

Cabe señalar aquí que durante los años en los que García Mérou estuvo radicado en Norteamérica conoció una cantidad considerable de ciudades, además de estudiar sistemáticamente temas ligados a la industria, la agricultura, la diplomacia y afines. La circunstancia única de vivir allí en momentos en los que se estaba reconfigurando el mapa geopolítico, y el involucramiento en sus dinámicas, se tradujeron en un perfil singular. Manuel Gálvez, por ejemplo, recordaba a García Mérou como un rara avis, por ser, quizás, el único argentino que podía mencionar con soltura nombres de "estadistas y escritores yankees". ${ }^{85}$

Este perfil decantó en un momento que podemos fechar difusamente entre el fin de la guerra y 1899; aunque en estos años todavía subrayaba en los documentos confidenciales que Estados Unidos, a instancias del presidente McKinley, se veía "ansioso de adquirir territorios lejanos y arrojar las bases de un imperio colonial", ${ }^{86}$ en el marco de sus libros y publicaciones que vieron luz pública, comenzó a dar cuenta de rasgos potencialmente reivindicables del país. En este sentido, sus miradas pueden resumirse en algunas consideraciones contundentes. Una de ellas, surgida durante una estadía en Chicago:

La vida americana está hecha de contrastes. En las mismas grandes ciudades de este país, al lado de los edificios majestuosos de veinte pisos de altura, hay

83 García Mérou, M., Estudios Americanos.

84 García Mérou, M., Historia de la diplomacia americana: política internacional de los Estados Unidos, I y II.

85 Gálvez, M., Recuerdos de la vida literaria. I. Amigos y maestros de mi juventud. En el mundo de los seres ficticios, p. 86.

86 Carta de Martín García Mérou a Amancio Alcorta Washington, 29/01/1899. Instituto Bibliográfico “Antonio Zinny”, Fondo Martín García Mérou, Caja 3. 
barrios enteros de casas de madera, con aceras del mismo material, en que habitan millares de seres humanos en un hacinamiento y promiscuidad que nada tiene que envidiar a las viejas capitales del antiguo continente”. ${ }^{87}$

Observaciones en este sentido no idealizaban los parámetros civilizatorios europeos; pero se mostraban abiertas a reconsiderar a Estados Unidos como un modelo, si bien en un marco diferente al conocido por Domingo F. Sarmiento o recuperado por Juan Bautista Alberdi. ${ }^{88}$ El escenario que despertó entusiasmo en García Mérou fue, justamente, el de la expansión económica y territorial, y la modernización material norteamericana. Si ya en sus Recuerdos literarios, publicados en 1891, había señalado: "los Estados Unidos [...] están bien lejos de desdeñar el desarrollo de los intereses intelectuales. Sus letras tienen representantes notables en todas las ramas de la producción inteligente", 89 al hacer una reseña de la ciudad de Boston se alegraba de ver en una misma ciudad una vida universitaria y cultural activa, y un desarrollo industrial próspero. ${ }^{90}$

En dirección complementaria, en varios de sus escritos sostuvo que la armonía de la sociedad norteamericana era una de las claves para entender las realidades del país. Resumió esta premisa con la siguiente pregunta “¿Qué talismán secreto posee la vida de estas democracias que así transforma y funde en su crisol lo más variado de caracteres de la raza humana y los eleva a la dignidad de ciudadanos, conscientes de su valer y respetuosos del deber y del derecho?"91

Entre los valores de la sociedad norteamericana destacó la "generosidad de estos hombres que algunas veces han empezado la vida desde los escalones más bajos de la escala social”, y se sirvió de la imagen del pioneer para dar cuenta de las virtudes cívicas de los ciudadanos norteamericanos. Por añadidura, la grandeza material norteamericana no le generó el rechazo que manifestaron varios de sus contemporáneos. En sus escritos se encuentran metáforas ligadas a las del gigantismo norteamericano, presentes ya en las observaciones de Domingo F. Sarmiento — con connotación positiva - y en otros intelectuales, como Paul Groussac — con signos negativos—,${ }^{92}$ pero en su caso ese gigantismo no está asociado a lo monstruoso o lo temible: "este

87 García, Mérou, Estudios Americanos, p. 15.

${ }_{88}$ Rodríguez Pérsico, A., Un huracán llamado progreso: utopía y autobiografía en Sarmiento y Alberdi.

89 García Mérou, M., Recuerdos literarios, p. 16

90 García Mérou, M., Estudios Americanos, pp. 5-14.

91 García Mérou, M., Estudios Americanos, p. 18.

92 Véase Bruno, P., "Un momento latinoamericano. Voces intelectuales entre la I Conferencia Panamericana y la Gran Guerra”, en Archilés, F. y M. Fuentes (eds.), Ideas comprometidas. Los intelectuales y la política. 
país extraordinario en que todo es grande, en que todo parece transportado a escala de aquellos habitantes de Saturno pintados por Voltaire en la historia de la peregrinación de Micrómegas". ${ }^{93}$

Estas observaciones generales sobre Estados Unidos se completan en su obra con una gran cantidad de datos y estadísticas sobre esferas de lo más diversas, relevadas o realizadas por él mismo. Así, por ejemplo, en el libro Apuntes económicos e industriales sobre los Estados Unidos documenta y describe fenómenos como el desarrollo industrial, los factores de producción — sus potencialidades y límites-, la estructura agraria, los mercados y los transportes, pero también analiza aspectos sociales, como los vinculados a la educación en distintos niveles, y el mundo del trabajo. ${ }^{94}$

Ya asentado este tono optimista, ${ }^{95}$ y abandonado el más crítico de los años de su llegada a Estados Unidos y la coyuntura de 1898, García Mérou asumió el desafío de pensar el expansionismo contemporáneo connotándolo de manera positiva en el marco de un clima de opinión que, como se destacó, avanzaba en sentido contrario. En su Historia de la diplomacia america$n a$, señala que su libro podía servir como guía a las nuevas generaciones que, desprendiéndose de los prejuicios sobre Estados Unidos, se permitieran avanzar en un conocimiento acabado de sus cualidades. ${ }^{96}$ Es allí donde define al imperialismo en los siguientes términos:

Me he visto conducido a investigar las tendencias de la política internacional americana y los procedimientos de su diplomacia. La última faz de dicha política, o lo que se llama imperialismo, no es sino la culminación lógica de una irresistible necesidad de expansión territorial que se manifiesta desde los albores de la vida independiente de la más grande de las democracias modernas. ${ }^{97}$

En suma, sus observaciones menos coyunturales se sostenían en dos pilares diferenciales en relación a sus contemporáneos. El primero descansa en sus conocimientos exhaustivos del país y en el reconocimiento de varias de sus contradicciones intrínsecas. El segundo reposa en sus interpretaciones

93 García Mérou, M., Estudios Americanos, p. 60.

94 García Mérou, M., Apuntes económicos e industriales sobre los Estados Unidos, p. 1.

95 A pesar de las resonancias que podrían identificarse entre estos pasajes de las ideas de Alexis de Tocqueville o Michel Chevalier no se han encontrado referencias explícitas a las mismas en los textos de García Mérou. Los autores más citados a la hora de argumentar son John Fiske, John Hay y Theodore Roosevelt.

96 La Historia de la diplomacia americana fue elogiada en Buenos Aires y en Estados Unidos y se convirtió en un libro clásico para estudiar el tema. Unas reseñas destacadas aparecidas en Estados Unidos se encuentran en The American Historical Review, vol. 11, núm. 3, 1906.

97 García Mérou, M., Historia de la diplomacia americana: política internacional de los Estados Unidos, tomo 2, p. 1. 
contra-intuitivas, en un contexto en que las críticas categóricas ante el imperialismo norteamericano eran las dominantes.

\section{CONSIDERACIONES FINALES}

El optimismo frente a las potencialidades del rol norteamericano no llevó a García Mérou a aceptar su intervencionismo de manera ciega. Los sucesos que decantaron en el principio de derecho internacional conocido como Doctrina Drago así lo constatan. Como es sabido, uno de los primeros episodios que marcó la presencia norteamericana en el continente tuvo lugar en la coyuntura de la definición de un problema limítrofe entre Venezuela y Gran Bretaña (que desde mediados del siglo XIX corría cada vez más al oeste el límite entre territorio venezolano y la Guayana Británica). Venezuela solicitó apoyo a los Estados Unidos para enfrentarse bélicamente con Gran Bretaña y el conflicto se resolvió cuando, en 1897, los norteamericanos lograron que los ingleses aceptaran un arbitraje internacional para resolver la cuestión limítrofe. ${ }^{98}$

En 1899 se resolvió el tema en París, y Venezuela fue representada en la ocasión por delegados norteamericanos. Años después, un conflicto que también involucraba a Venezuela mostró cómo se desplegaría el rol de Estados Unidos a la hora de garantizar que una nación latinoamericana asumiera la responsabilidad del pago de las deudas contraídas con el exterior. Cuando Alemania, Inglaterra e Italia bloquearon, en 1902, los puertos venezolanos para exigir el pago a sus deudores, Teodoro Roosevelt asumió el rol de mediador del conflicto, resuelto en el Tribunal de La Haya a favor de las potencias europeas en 1904, y garantizó a los países que reclamaban el pago de la deuda que Venezuela asumiría el compromiso del pago bajo la guía norteamericana. ${ }^{99}$ Un doble juego de fuerzas apareció con claridad en este episodio. Mientras que, por un lado, Estados Unidos se convertía en el garante internacional del cumplimiento de los compromisos financieros de América Latina, por otro, quedaba en evidencia la celosa actitud de la nación del norte ante el potencial resurgir de la presencia europea en la región.

Luego del bloqueo que las potencias europeas realizaron en Venezuela en 1902 y de la mediación norteamericana, algunas voces comenzaron a mostrar su preocupación por la fuerza internacional que estaba concentrando el país del norte. En ese contexto, el Ministro de Relaciones Exteriores y

98 Véase Scarfi, J.P., The Hidden History of International Law in the Americas. Empre and Legal Networks, pp. 70-74.

99 Puede verse: Deas, M., "Venezuela c. 1870-1930", en Bethell, L. (coord.) Historia de América Latina, vol. 10, pp. 314-329. 
Culto argentino, Luis María Drago, escribió un texto mostrando su alarma por la situación venezolana y solicitó a Martín García Mérou que, en tanto representante argentino, mediara para la presentación del mismo frente al presidente norteamericano. El debate sobre la propuesta de Drago tuvo lugar en las reuniones de la II Conferencia Panamericana, realizada en México en 1901-1902, en la que García Mérou representó a la Argentina junto con Antonio Bermejo y Lorenzo Andon.

De estas circunstancias surgió la Doctrina Drago, la cual focalizaba su atención en la idea de que la existencia de deudas con el exterior no podía ser motivo para justificar las intervenciones armadas ni la ocupación de territorios latinoamericanos por fuerzas europeas. La Doctrina Drago postulaba, a la vez, dos cuestiones: por un lado, reforzaba el texto de la Doctrina Monroe y, por otro, demostraba que surgían en América Latina voces de alerta ante las ocupaciones e intervenciones directas ejecutadas por Europa, pero también por los Estados Unidos. García Mérou celebraba en informe oficial a Drago los elogios recibidos por la doctrina y daba cuenta de los halagos y conformidad frente a "nuestras vistas" en política internacional. ${ }^{100}$

Ya en los años posteriores, García Mérou, quien falleció en 1905, no pudo ser testigo de la atención que la Doctrina Drago asumió en la III Conferencia Panamericana de 1906 y en la Conferencia de La Haya de 1907. Tampoco vio los efectos del Corolario Roosevelt, dentro de cuyos argumentos se matizaban algunas ideas presentes en la Doctrina Monroe y se justificaba la presencia y la intervención norteamericana en el Caribe, bajo las auto-adjudicadas misiones de garantizar la paz política de la región y sanear las finanzas de los países intervenidos.

García Mérou residió en Estados Unidos por casi una década antes de que se desplegaran estos últimos sucesos descritos. Durante esos años de su trayectoria diplomática, la Argentina atravesó un período intenso en lo referido a sus relaciones exteriores; durante la presidencia de Luis Sáenz Peña (1892-1895) se firmó con Chile un Protocolo Adicional al Tratado de Límites que se había firmado en 1881; se comenzaron a restablecer relaciones con la Santa Sede (interrumpidas en 1884) y se reajustó el tratado Quirno Costa-Vaca Guzmán por la cuestión de la Puna de Atacama — por la definición de límites entre Chile, Argentina y Bolivia— (1893), reafirmado por el Protocolo Rocha-Cano (1895); a la vez, comenzó lo que los historiadores de la política exterior llaman una "carrera armamentista" con Chile. Durante el mandato presidencial de José Evaristo Uriburu (1895-1898) se recrudeció la tensión con Chile, y la compra de armamentos y naves se intensificó; se

${ }^{100}$ Carta-informe de Martín García Mérou a Luis María Drago, Washington 23/05/1903. Archivo Histórico de Cancillería Argentina, Serie Misiones al Exterior, Libro 19. 
acató el Laudo Cleveland de 1895 para resolver la cuestión limítrofe con Brasil, conocida como Misiones-Palmas. Ya en el transcurso de la segunda presidencia de Julio A. Roca (1898-1904) se bregó por un acercamiento diplomático con Brasil (escenificado por las visitas cruzadas de Roca a Brasil en 1899 y del presidente Campos Salles a Argentina en 1900), se reanudaron relaciones con la Santa Sede (1903), se firmaron los Pactos de Mayo con Chile en 1902; Argentina declaró su neutralidad ante la guerra entre Estados Unidos y España de 1898 y se participó en la II Conferencia Panamericana, en la que se consolidó la figura de Drago en el Derecho internacional; por mencionar solamente algunos sucesos y acuerdos destacados.

En Estados Unidos, por su parte, se produjeron reacomodamientos geopolíticos a la luz de varios de los procesos ya mencionados a lo largo de este ensayo. Para fines del siglo XIX los Estados Unidos se habían convertido en una potencia en pleno despliegue. En el marco de la competencia imperialista internacional, la influencia de Gran Bretaña sobre América Latina comenzó a ser sustituida, al menos en parte, por la norteamericana. El expansionismo estadounidense se desplegó en un contexto en el que se estaban desarrollando al interior del país sentimientos de nacionalismo de corte agresivo, presente en obras y folletos que bregaban por un decisivo imperialismo colonial —se destacan entre ellos: Josiah Strong, Our country (1885); John Fiske, Manifest Destinity (1885); Alfred Mahan, The influence of sea power on history (1890)—. Los historiadores coinciden en señalar que el nacionalismo enfervorizado e imperialista se vio abonado por las ideas del "destino manifiesto", que colocaba a los Estados Unidos en el rol de propagador de los valores morales, políticos y religiosos anglosajones. En paralelo, el panamericanismo propiciado desde el Norte, y con escenario privilegiado en las Conferencias Panamericanas, marcaba el ritmo al surgimiento del antiimperialismo latinoamericano en sus primeras manifestaciones.

García Mérou bregó desde su cargo diplomático por ser un articulador entre estos dos escenarios y sus dinámicas. A juzgar por lo que se analizó a lo largo del texto, puede aventurarse que quizás el Estado argentino, al menos durante estos años, no tenía definido si le interesaba mantener en el país del Norte una "diplomacia de poetas" o una "diplomacia de acorazados" en lo que respecta a la definición de política exterior. ${ }^{101}$ Para Argentina todavía parecía ser prioridad definir sus propios límites y sus acuerdos diplomáticos

101 "Diplomacia de poetas" y "diplomacia de acorazados" son expresiones usadas en varias fuentes de la época para hacer referencia a diplomacias de carácter más "blando" o de corte netamente cultural y otras de carácter más "duro”, sustentadas, por ejemplo, en competencias armamentistas. 
con Chile, Brasil y Bolivia. Éstos eran los problemas que los periódicos de Buenos Aires cubrían en sus incipientes columnas de noticias internacionales. El estallido de la guerra de 1898, como se sugirió ya, había quizás sumado incentivos para tratar de pensar el escenario internacional a escala continental, y no solamente sudamericana. Las migraciones de algunos intelectuales latinoamericanos propiciaban también una circulación de información, ideas e interpretaciones sobre los destinos americanos. ${ }^{102}$ Piénsese como caso testigo el de José Martí, que cubrió para el periódico La Nación la I Conferencia Panamericana —sus crónicas fueron reproducidas en varios periódicos latinoamericanos- Con estos telones de fondo, García Mérou definió una agenda para vestir el traje que consideró más adecuado para ser un diplomático argentino en Estados Unidos. Como se señaló ya, abocó gran parte de su vida al servicio exterior de la nación, con los claroscuros y contrastes que eso significó, a juzgar por los indicios de las trayectorias aquí relevadas, en las últimas décadas del siglo XIX y los inicios del XX. ${ }^{103}$

A la hora de pensar el rol de los diplomáticos en la Argentina del período en el que aquí se hizo foco, se ha subrayado en ocasiones que los cargos de este tipo operaban como premios -o castigos, como puede sugerir el caso de Eduardo Wilde- para figuras que ejercían roles en la política. A su vez, David Viñas, por ejemplo, vinculó en distintas ocasiones a la diplomacia con el ocio, los tiempos muertos y el aburrimiento — sobre todo en las semblanzas que ofrece de Lucio V. Mansilla y Vicente Quesada-. La trayectoria de García Mérou no encaja en estas caracterizaciones más convencionales. Su itinerario es bastante particular en relación a varios de sus contemporáneos. Para él la diplomacia no fue una ocupación más o intercalada entre otras, sino el vector de su trayectoria pública. La mayor parte de su vida estuvo instalada en otras geografías y convirtió sus residencias, como la de Estados Unidos aquí tratada, en ocasiones para recopilar materiales, investigar las sociedades que lo acogieron, y traducir en textos sus experiencias y análisis. Ejerció la diplomacia con márgenes de autonomía considerables como para considerar que solamente se trataba de un funcionario al servicio de rígidas políticas estatales. Los distintos momentos de su itinerario permiten, quizás, repensar qué significaba ser un diplomático argentino en el cambio de siglo, sobre todo, en latitudes donde las relaciones comerciales no marcaban las pautas de comportamiento y protocolo. Por último, el estudio de las estancias en legaciones, como la aquí estudiada, arroja también luz para ver los

102 Ramos, J., “Hemispheric Domains: 1898 and the Origins of Latin Americanism”, en Journal of Latin American Cultural Studies, núm. 10, 2001, pp. 237-251.

103 Bruno, P., Vidas diplomáticas: Vicente Quesada, Eduardo Wilde, Estanislao Zeballos, Martín García Mérou. 
puntos de encuentro y desencuentro entre ciertos climas intelectuales a escala regional considerados dominantes en la historiografía (antiyankeesmo, antiimperialismo, latinoamericanismo) y las modulaciones más personales de los actores que vivían en estos marcos tensionados entre rutinas cotidianas y producción de saberes sobre lo que en aquella época se definía en términos más bien difusos como "lo internacional".

\section{BiBLIOGRAFÍA}

AA.VV., España y Estados Unidos. Función dada en el Teatro de la Victoria el 2 de mayo de 1898. Bajo el patrocinio del Club Español de Buenos Aires, a beneficio de la Suscripción Nacional Española. Folleto, 1898.

Auza, Néstor Tomás, "Martín García Mérou, un estudioso de la sociedad americana de fines del siglo XIX y comienzos del XX”, Investigaciones y Ensayos, núm. 18, enero-junio de 1975, pp. 311-333.

Bruno, Paula, "Estados Unidos como caleidoscopio. Ensayo sobre las observaciones de viajeros y diplomáticos del fin de siglo”, Revista Complutense de Historia de América, vol. 39, 2013, pp. 23-38.

-, "Lecturas de Miguel Cané sobre la función de la prensa en las sociedades modernas”, Cuadernos Americanos, núm. 123, 2008, pp. 113-138.

, "Mamuts vs. hidalgos. Lecturas de Paul Groussac sobre Estados Unidos y España en el fin-de-siglo”, Alexandra Pita González y Carlos Marichal Salinas (compiladores), Pensar el antiimperialismo. Ensayos de historia intelectual latinoamericana 1900-1930, México, El Colegio de México/Universidad de Colima, 2012, pp. 43-68.

, "Martín García Mérou entre Brasil, Argentina y Estados Unidos. Observaciones para pensar el fin-de-siglo americano", AA.VV., Gregorio Weinberg: escritos en su honor. Premio Gregorio Weinberg a la Investigación en Historia de la Educación, la Ciencia y la Cultura Latinoamericanas, Buenos Aires, CLACSO, 2017, pp. 25-54.

, "Un momento latinoamericano. Voces intelectuales entre la I Conferencia Panamericana y la Gran Guerra”, en Ferrán Archilés y Maximiliano Fuentes (editores.), Ideas comprometidas. Los intelectuales y la política, Madrid, Akal, pp. 57-77.

—_, Martin García Mérou. Vida intelectual y diplomática en las Américas, Bernal, Universidad Nacional de Quilmes, en prensa.

— Siglo XXI Editores, 2011.

_- Paula, Vidas diplomáticas: Vicente Quesada, Eduardo Wilde, Estanislao Zeballos, Martín García Mérou, mimeo.

Cagni, Horacio, La guerra hispanoamericana y el inicio de la globalización, Buenos Aires, Olcese, 1999. 
Campbell, Joseph, The Spanish-American War: American Wars and the Media in Primary Documents, Westport, Greenwood Press, 2005.

- Yellow Journalism: Puncturing the Myths, Defining the Legacies, Westport, Praeger, 2001.

Cané, Miguel, En viaje, 1881-1882, Paris, Garnier Hermanos, 1884.

Canogar, Daniel, Ciudades efímeras: exposiciones universales, espectáculo y tecnología. Madrid, Julio Ollero Editor, 1992.

Celada Domínguez, Gregoria y Rita Giacalone, "Revista de Derecho, Historia y Letras (1898 - 1923). Estudio e índice general”, en IUSHISTORIA, núm. 4, 2007 y núm. 5, 2008, edición digital disponible en: www.salvador.edu.ar/juri/reih/index.htm

Cisneros, Andrés y Carlos Escudé, Historia general de las relaciones exteriores de la República Argentina, Buenos Aires, Cari, varios años de edición. Disponible en <http://www.argentina-rree.com/historia_indice00.htm>.

Conn, Steve, Museums and American Intellectual Life, 1876-1926, Chicago, Chicago University Press, 1998.

Courtney Letts de Espil, La segunda presidencia de Roca vista por los diplomáticos nortemaericanos, Buenos Aires, Paidós, 1972.

De Pantoja, Domingo (seudónimo de Vicente Quesada), Los Estados Unidos y la América del Sur. Los yankees pintados por sí mismos, Buenos Aires, Imprenta, Litografía y Encuadernación de J. Peuser, 1893.

Deas, Malcolm, "Venezuela c. 1870-1930”, en Leslie Bethell (editor), Historia de América Latina, vol. 10, Barcelona, Crítica, 1992, pp. 314-329.

Del Solar, Alberto, La Doctrina Monroe y la América Latina (Conferencia leída en el Ateneo el 20 de junio de 1898), Buenos Aires, Jacobo Peuser, 1898.

Díaz Quiñones, Arcadio, Sobre los principios. Los intelectuales caribeños y la tradición, Bernal, Universidad Nacional de Quilmes, 2006.

Etchepareborda, Roberto, Zeballos y la política exterior argentina, Buenos Aires, Pleamar, 1982.

Follari, Rodolfo, “Aspectos de la política de los Estados Unidos en la correspondencia diplomática de Vicente G. Quesada”, en Nuestra Historia. Revista de Historia de Occidente, núm. 41-42, 1994, pp. 331-353.

Gálvez, Manuel, Recuerdos de la vida literaria. I. Amigos y maestros de mi juventud. En el mundo de los seres ficticios, Buenos Aires, Taurus, 2002.

García Mérou, Martín, Apuntes económicos e industriales sobre los Estados Unidos, Buenos Aires, Félix Lajouane, 1905.

, El Brasil intelectual. Impresiones y notas literarias, Buenos Aires, F. Lajoune, 1900.

-, Estudios americanos, Buenos Aires, Félix Lajouane, 1900.

—. Historia de la diplomacia americana: política internacional de los Estados Unidos, Tomos I y II, Buenos Aires, Félix Lajouane, 1904.

\section{8}


García Sebastiani, Marcela, "España fuera de España. El patriotismo español en la emigración argentina: una aproximación”, Hispania, vol. 73, núm. 244, 2013, pp. 469-500.

García, Ignacio, “Apoyo a los españoles a la causa de la Cuba española. El caso argentino”, en Estudios Sociales, núm. 19, 2000, pp. 85-104.

González-Stephan, Beatriz y Jens Andermann, (editores.), Galerías del progreso: Museos, exposiciones y cultura visual en América Latina, Rosario, Beatriz Viterbo Editora, 2006.

Halperin Donghi, Tulio, "España e Hispanoamérica: miradas a través del Atlántico (1825-1975)”, en Id., El espejo de la historia. Problemas argentinos y perspectivas latinoamericanas, Buenos Aires, Sudamericana, 1998, pp. 65-110.

International Bureau of The American Republics (compiled by), Argentina Republic. A geographical sketch with special reference to economic conditions, actual development, and prospects of future growth, Washington, 1903.

López, Carolina, "Los intelectuales argentinos frente a la independencia cubana de 1898: último bastión imperialista y nuevo status colonial”, Araucaria. Revista Iberoamericana de Filosofía, Política y Humanidades, núm. 26, 2011, pp. 3-25.

McGann, Thomas, Argentina, Estados Unidos y el sistema interamericano, 18801914, Buenos Aires, Eudeba, 1960.

Mösslang, Markus y Torsten Riotte (editores), The Diplomats' World: A Cultural History of Diplomacy, 1815-1914, Londres, The German Historical Institute/Oxford University Press, 2008.

Pepper, Charles, Every Day Life in Washington whit pen and camera, New York, The Christian Herald, 1900.

Peterson, Harold, La Argentina y los Estados Unidos, 1810-1914, Buenos Aires, Hyspamerica, 1964.

Philadelphia Commercial Museum (prepared and published by), Commerce of Latin American. A Brief Statistical Review, 1903.

Pletcher, David, Diplomacy of Trade and Investment: American Economic Expansion in the Hemisphere, 1865-1900, Columbia, University of Missouri Press, 1998.

Quesada, Vicente, Recuerdos de mi vida diplomática. Misión en Estados Unidos (1885-1892), Buenos Aires, Librería de Jesús Menéndez, 1904.

Ramos, Julio, "Hemispheric Domains: 1898 and the Origins of Latin Americanism”, Journal of Latin American Cultural Studies, vol. 10, núm. 3, pp. 237-251.

Raymont, Henry, Vecinos en conflicto. La historia de las relaciones entre Estados Unidos y Latinoamérica desde Franklin Delano Roosevelt hasta nuestros días, México, Siglo XXI, 2007.

Rodríguez Pérsico, Adriana, Un huracán llamado progreso: utopía y autobiografía en Sarmiento y Alberdi, Washington, Organización de los Estados Americanos, 1992. 
Scarfi, Juan Pablo, "La emergencia de un imaginario latinoamericanista y antiestadounidense del orden hemisférico: de la Unión Panamericana a la Unión Latinoamericana (1880-1913)", Revista Complutense de Historia de América, vol. 39, 2013, pp. 81-104.

Scarfi, Juan Pablo, The Hidden History of International Law in the Americas. Empire and Legal Networks, New York, Oxford University Press, 2017.

Sheinin, David, "Una paradoja comercial-cultural: la Argentina, España y Estados Unidos en la época de la guerra hispano-americana”, Trabajos y Comunicaciones, número 26-27, 2000-2001, pp. 187-209.

- Searching for authority: Pan Americanism, diplomacy and politics in United States-Argentine relations, 1910-1930, New Orleans, University Press of the South 1998.

Solveira, Beatriz La evolución del servicio exterior argentino entre 1852 y 1930, Córdoba, Centro de Estudios Históricos, 1997.

Spyer Dulci, Teresa, As Conferências Pan-americanas. 1889-1928. Identidades, União Aduaneira e Arbitragem, São Paulo, Alameda, 2013.

Terán, Oscar, "El primer antiimperialismo latinoamericano", en Id., En busca de la ideología argentina Catálogos, Buenos Aires, 1986, pp. 85-97.

Viñas, David, Literatura argentina y realidad política. De los jacobinos porteños a la bohemia anarquista, Buenos Aires, Sudamericana, 1995.

— De Sarmiento a Dios. Viajeros argentinos a USA, Buenos Aires, Sudamericana, 1998.

Wilde, E., Cosas mías y ajenas, Tomo X de Obras Completas, Buenos Aires, Imprenta Belmonte, 1939.

Zeballos, E., La concurrencia universal y la agricultura en ambas Américas, Washington D.C., Gibson Bros. Impresores, 1894.

\section{FUENTES INÉDITAS}

Archivo Histórico de Cancillería Argentina, Serie Diplomática y Consular y Serie Misiones al Exterior.

Instituto Bibliográfico “Antonio Zinny”, Fondo Martín García Mérou.

Fondo Documental del Mueso Roca.

\section{PUblicaciones PERIÓdicAS}

La Nación.

Caras y Caretas.

Revista de Derecho, Historia y Letras.

La Ilustración Sud-Americana. Periódico Ilustrado de las Repúblicas Sudamericanas. 